\title{
Numerical modelling of the evolution of a river reach with a complex morphology to help define future sustainable restoration decisions
}

\author{
Rabab Yassine ${ }^{1,2,3^{*}}$, Ludovic Cassan ${ }^{1}$, Hélène Roux ${ }^{1}$, Olivier Frysou ${ }^{3}$, and François Pérès ${ }^{2}$ \\ ${ }^{1}$ Institut de Mécanique des Fluides de Toulouse (IMFT), Université de Toulouse, CNRS, Toulouse, France \\ ${ }^{2}$ INP/ENIT, LGP, Université de Toulouse, Tarbes, France \\ ${ }^{3}$ Pays de Lourdes et des Vallées des Gaves, Lourdes, France \\ ${ }^{*}$ Currently at EGIS Business Unit: Major Structures, Water, Environment, Energy, Montpellier, France
}

Correspondence: Rabab Yassine (rabab.yassine@egis.fr)

\begin{abstract}
The evolution of river morphology is very complicated to predict, especially in the case of mountain and Piedmont rivers with complex morphologies, steep slopes, and heterogeneous grain sizes. The "Lac des Gaves" (LDG) reach, located within the Gave de Pau river in the Hautes-Pyrénées department, France, has precisely the complex morphological characteristics mentioned above. This reach has gone through severe sediment extractions for over 50 years, leading to the construction of

two weirs for riverbed stabilisation. Two large floods resulted in changes in the LDG's hydromorphological characteristics as it went from a single channel river section to a braided river reach. In this study, a 2D hydromorphological model is developed with the TELEMAC-MASCARET system to reproduce the evolution of the channel following a flood that occurred in 2018. The model's validity is assessed by comparing the simulated topographic evolution to the observed one. The results reveal the challenge to choose well-fitted sediment transport equations and friction laws that would make it possible to reproduce such complex morphology. Even if the exact localisation of the multiple channels forming the braided nature of the LDG was challenging to reproduce, our model could provide reliable volumetric predictions as it reproduces the filling of the LDG correctly. The influence of the two weirs on the river's current and future morphology is also studied. The aim is to provide decision-makers with more reliable predictions to design suitable restoration measures for the LDG reach.
\end{abstract}

\section{Introduction}

Flood events can lead to considerable sediment transport that has an influence on flow dynamics. Understanding the interactions between flow dynamics and morphological changes is thus of growing interest in the research community (Guan et al., 2015), especially in mountainous regions where the interactions between water and sediments are complex. Rickenmann et al. (2016) highlighted the critical influence of sediment transport during flood events in alpine catchments and the inherent damages (Reisenbüchler et al., 2019). They showed that morphodynamics could increase the flood intensity leading to more dramatic consequences. This is particularly true in mountainous catchments where the important sediment supply from the upstream torrents and torrential rivers may expose the downstream fluvial system to great danger during flood episodes and increase the related damages (Reid et al., 2007; Badoux et al., 2014). For instance, channel conveyance capacity can decrease when consequent amounts of sediments are deposited within the riverbed, increasing river diversion risks toward surrounding areas 
https://doi.org/10.5194/esurf-2021-91

Preprint. Discussion started: 26 January 2022

(c) Author(s) 2022. CC BY 4.0 License.

(Badoux et al., 2014; Recking et al., 2012; Reid et al., 2007; Rickenmann et al., 2016; Rinaldi and Darby, 2007). Understanding sediment transport and especially bedload is thus essential for establishing a coherent flood control plan and defining sustainable restoration strategies (Kang and Yeo, 2015). Besides safety issues, bedload transport, combined with water discharge, is considered a fundamental driver of river condition. They can affect habitat, aquatic ecosystems, river stability, and natural hazards (Wohl et al., 2015).

River restoration for flood prevention purposes is generally related to achieving a sufficient degree of protection through the design of solutions ranging from the installation of physical infrastructures to alternative measures for risk reduction (ArnaudFassetta et al., 2009). Reliable numerical modelling of flow and sediment dynamics with a good field expertise can be useful in this case for better river management. Numerical models can provide quantified answers on the configuration of flows during a flood event, which can be challenging to measure on the ground (Chapuis, 2012). Morphological models coupled to hydrodynamic ones (Reisenbüchler et al., 2019) have now been applied to various rivers of different sizes and characteristics to examine the evolution of alluvial river channels (Carr et al., 2015; Guan et al., 2015, 2016; Ham and Church, 2012; Rinaldi and Darby, 2007; Tal and Paola, 2010; Tu et al., 2017). This means that the hydrodynamic model provides information on the turbulence, shear stress, and flow to the morphological model that uses it to compute sediment transport rates and bed evolution (i.e. erosion and deposition rates). However, sediment transport rates are usually calculated with empirical formulas (Meyer-Peter and Müller, 1948; van Rijn, 1984; Einstein, 1950; Wilcock and Crowe, 2003) mostly derived from laboratory experiments with numerous simplifications of real field conditions. To have a physically realistic simulation, it is necessary to provide the model with realistic bedload transport rates to introduce reliable boundary conditions and, thus, a robust model. Besides, the morphological processes occurring in the field are often simplified. This is why a field investigation and scientific monitoring before developing the model must be very well conducted to help the model operator criticise and improve its predictive abilities.

When the model is well-calibrated and validated enough on real field data, the main advantage of modelling is that it is possible to simulate restoration scenarios, challenging to implement in the field (Arnaud, 2012). Two-dimensional (2D) numerical models are increasingly being used for flood modelling and river management in general. The majority of these models consider the resolution of Shallow Water Equations (SWE) (Hervouet, 2003). As the impacts of morphological modifications on flow dynamics can be considerable, considering sediment transport is of primary importance when the purpose is to design sustainable restoration solutions. Morphodynamic simulations are thus required to represent bed evolution following the implementation of a restoration measure, especially in Piedmont rivers, where these factors can highly influence hydrodynamics.

The effects of the interactions between hydrodynamics and morphodynamics have proved to be particularly dramatic during the flood of 2013, an almost 100-year return period event, that severely impacted the "Gave de Pau" catchment, especially the "Lac des Gaves" reach in the Hautes-Pyrénées department in France that we will name LDG in this article. This former artificial lake within the "Gave de Pau"'s riverbed, delimited by two weirs, has undergone years of sediment extractions. These activities lead to a robust hydromorphological imbalance that is disturbing the watercourse's normal functioning in this area. Today, after the flood of June 2013, the lake is almost completely filled with sediments, which may lead to river diversion towards populated areas. Upstream the second weir, the "Gave de Pau", has precisely the complex morphological properties 
mentioned above. In this area, the river presents specific aspects of Piedmont rivers, characterized by very heterogeneous grain sizes and a complex braided morphology, which indicates considerable sediment delivery from the upstream catchments. On the opposite, downstream the weir, an active channel shrinkage is observed, characteristic of a sediment deficit and a sediment discontinuity that led to serious ecological damages and navigation problems.

The TELEMAC-MASCARET ${ }^{1}$ modelling system has been considered well suited to perform 2D morphodynamic simulations on the LDG reach. However, it is necessary to note that this type of calculation has been little explored on such complex morphologies specific to Piedmont rivers. Most simulations considering sediment transport with this model have been carried out on laboratory cases or real case studies with lower slopes and/or simpler morphologies (Lepesqueur et al., 2019; Orseau et al., 2021). Thus, it is interesting to evaluate the model's performance on such kind of complex morphology.

The present work serves to illustrate: (1) the ability of a 2D numerical model to reproduce hydromorphological processes in complex river morphology, (2) the performance of different friction laws and sediment transport equations, and (3) how

70 a 2D hydromorphological model can help river managers to better understand the dynamics within the LDG reach in order to evaluate the impacts of a given restoration measure on the system and to adopt a sustainable and rational management orientation (De Linares, 2007).

The paper is organized as follows: section 2 introduces the study site and its characteristics. Section 3 describes the model with an emphasis on the friction laws and bedload formula. Section 4 presents the methodology to implement the hydromorphological model on the LDG area as well as the performance evaluation. The results are detailed and analyzed in section 5, with special attention to the sensitivity of the simulated behaviour with respect to the friction laws and the bedload formula. The main findings are summarized in section 6.

\section{Study area}

\subsection{The "Gave de Pau" catchment}

80 The "Gave de Pau" watershed (Fig. 1) is located in the western Pyrenees between the lowland of Lourdes (420 m asl) and the Spanish border in the south, where the highest French Pyrenean peaks culminate (Vignemale $3298 \mathrm{~m}$ asl, Taillon $3144 \mathrm{~m}$ asl). The "Gave de Pau" River originates in the well-known "Cirque de Gavarnie" around $2600 \mathrm{~m}$ asl (UNESCO World Heritage). The upstream part of the catchment has typical mountainous characteristics described by steep slopes, important sediment transport, high-water seasons observed between the end of spring and the beginning of summer, and a very dense hydrographic network. The two rivers constituting the "Gave de Pau" main stream are the "Gave de Gavarnie" (right bank) and the "Gave de Cauterets" (left bank). In high flow seasons, these two watercourses showed that they could transport significant amounts of sediments. They are thus considered as the primary sources of sediments coming from the upstream part of the catchment and deposited in the downstream central valley of Argelès-Gazost, where the LDG and most of the stakes are located (Fig. 2).

\footnotetext{
${ }^{1}$ http://www.opentelemac.org/
} 

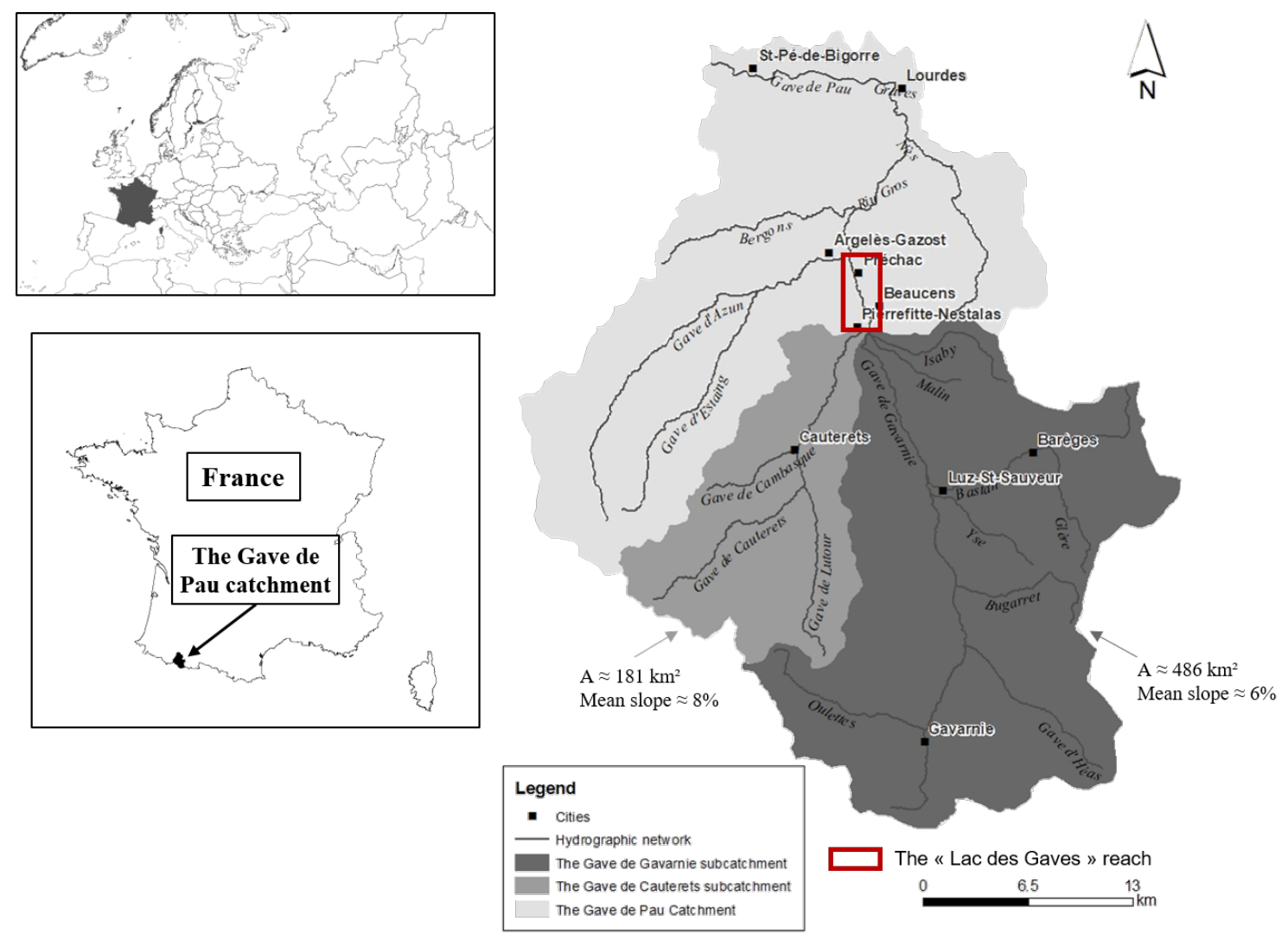

Figure 1. The "Gave de Pau" catchment and its main upstream sub-catchments: the "Gave de Cauterets" and the "Gave de Gavarnie" subcatchments ( $\mathrm{A}$ is the drainage area and the mean slope of the watercourses is also introduced). The LDG reach is represented by the red rectangle between the cities of Pierrefitte-Nestalas and Argelès-Gazost, Hautes-Pyrénées, France

\subsection{The LDG reach}

90 The LDG (Fig. 2) is an artificial lake located in the main stream of the "Gave de Pau" river. Like many rivers and lakes worldwide, it has gone through very intensive sediment extractions estimated to be around four million cubic meters over the past century. These activities led to constructing two weirs, one upstream and one downstream of the lake, to stabilize the riverbed. The large flood of 2013 highlighted a critical amount of impairments at the catchment scale, especially within this reach. It showed that the lake is now acting like a sediment trap blocking all the sediments coming from the upstream mountain streams. A brutal longitudinal profile discontinuity is observed and leads to an increased risk of river diversion towards populated areas, destruction of hydraulic structures' foundations, shrinkage of the active channel, a global incision (more than 3 meters), to name a few. This is mainly due to the LDG reach position, which is immediately located after the junction of the two mountain streams presented above. 

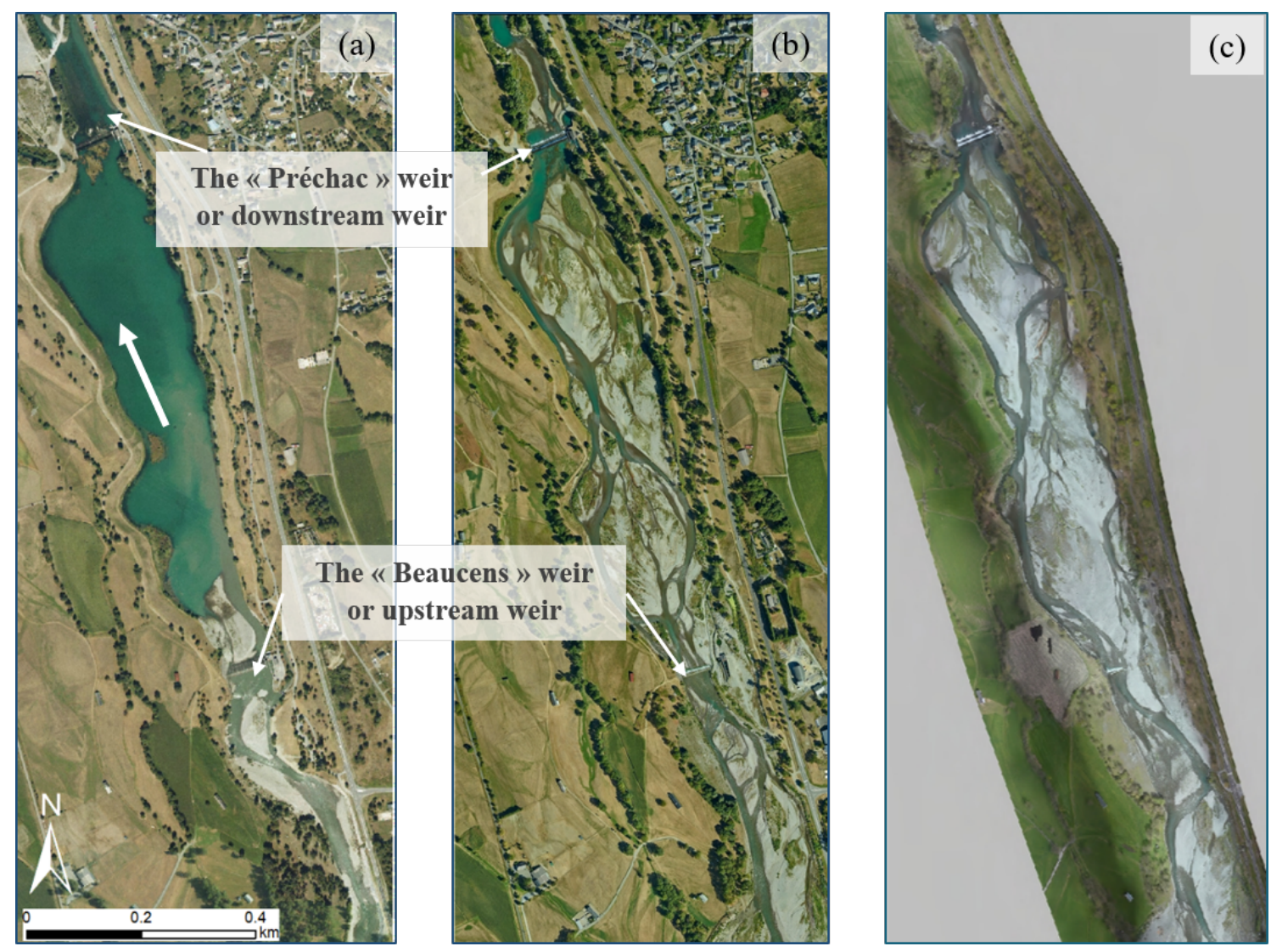

Figure 2. Morphological changes observed in the LDG reach. Aerial photo in $(\boldsymbol{a}): 2006,(\boldsymbol{b}): 2016$ after the flood of June 2013 and $(\boldsymbol{c}): 2019$ after the flood of June 2018 (source: IGN BD ORTHO, PLVG)

\subsection{Flood events}

Like several research (Blanpied, 2019) and engineering projects (IDEALP, 2014; PLVG, 2015; SUEZConsulting, 2019), this work was initiated by the exceptional flood of June 2013 that had a very strong impact on the entire central Pyrenees. This extreme event was caused by heavy rainfall combined with rapid and abundant snowmelt due to a brutal increase in temperature after a very cold spring. The peak discharge was estimated to be about $742 \mathrm{~m}^{3} / \mathrm{s}$ in Lourdes, corresponding to a 100-year return period flood compared to $90 \mathrm{~m}^{3} / \mathrm{s}$ annually in the same period. Besides the two casualties and the catastrophic material damage estimated at nearly 300 million of euros, this event has demonstrated the major influence of sediment transport in the hydromorphological dynamic of the catchment's streams. In fact, the extreme hydrology combined to a very high rate of sediment delivery from the upstream catchments exposed the downstream fluvial system to great danger in terms of very important sediment depositions, serious bank erosions that caused the collapse of roads and buildings, destruction of hydraulic structures' foundations and significant ecological damages (Fig. 3). 
During this event, the LDG acted like a sediment trap as it intercepted almost all the sediments coming from the upstream catchment (Fig. 2). Its morphology completely changed as it went from a lake/single-channel river section to a braided river reach. Five years after the flood of June 2013, another highly morphogenetic but of lesser magnitude flood occurred in June 2018. The peak discharge was estimated to be about $332 \mathrm{~m}^{3} / \mathrm{s}$ corresponding to a 10-year return period. Even if the damages are not comparable to the ones caused by the flood of 2013, the 2018 flood event greatly impacted the morphology of all the watercourses of the Gave de Pau catchment and exacerbated the filling phenomenon in the LDG. Today, the lake is almost completely filled, and avulsion risks are observed as the left bank elevation is lower than the bed elevation.
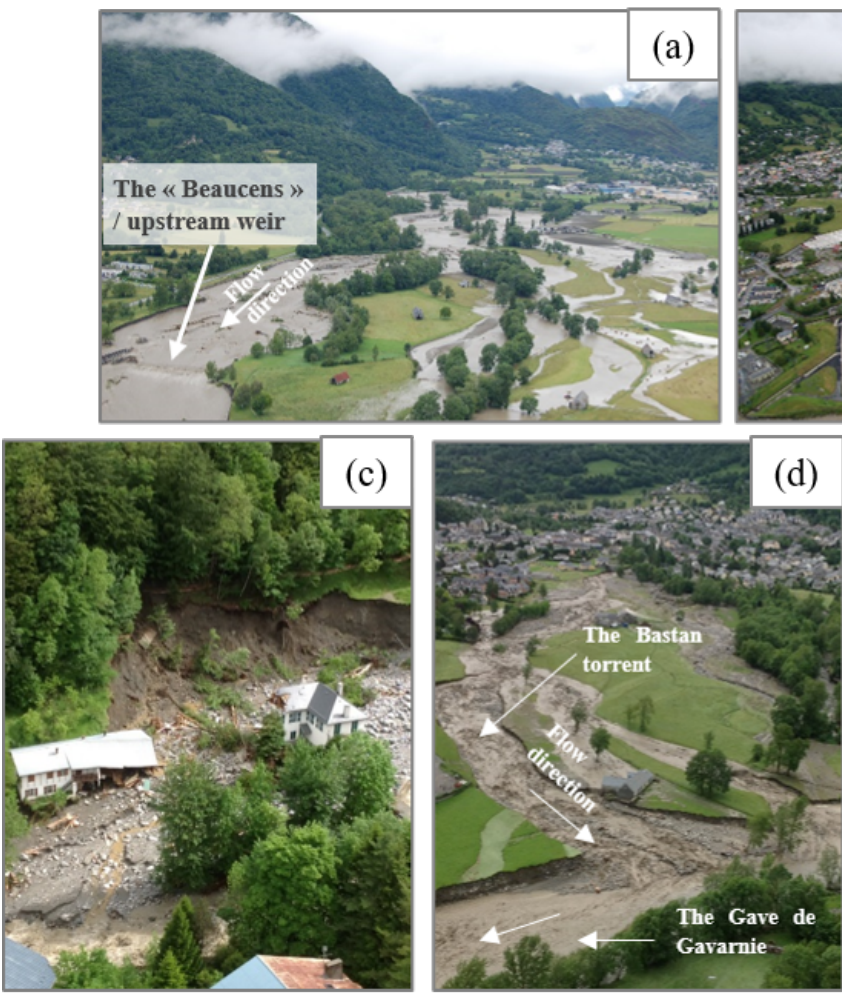

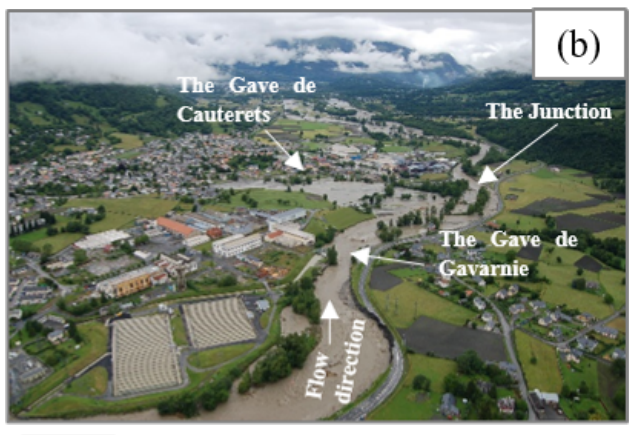

(d)

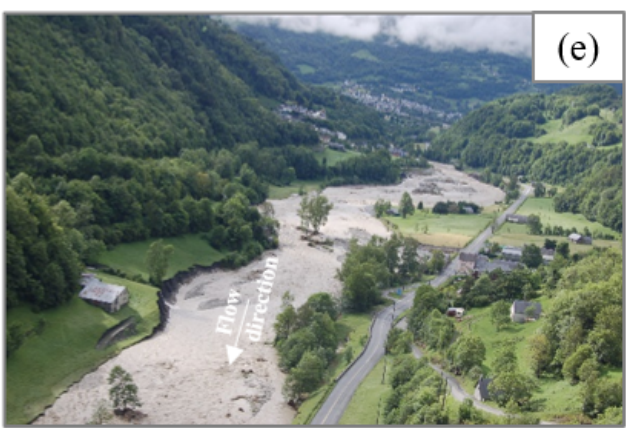

Figure 3. Some examples of damages caused by the flood of June 2013 at different locations and different streams. (a) The upstream part of LDG reach during the flood. This photo illustrates the river avulsion that occurred; the riverbed created few channels in the Adast plain: left bank (Upstream (south) view), (b) the "Gave de Gavarnie" and "Gave de Cauterets" at their junction. During the event, the erosion of the "Gave de Gavarnie's" right bank destroyed the main access road, and the villages of Pierrefitte and Soulom were flooded by the "Gave de Cauterets", (c) significant erosions and destruction of buildings located in the "Gave de Cauterets" active channel, (d) the "Bastan" torrent and the "Gave de Gavarnie" at their junction. This photo illustrates the important morphological activities that were engaged during the flood at this location, $(\boldsymbol{e})$ the "Gave de Gavarnie" at the Saligos plain immediately after its junction with the "Bastan" torrent. Significant bank erosions are observed in this area (PLVG, RTM, DDT65) 


\subsection{Restoration implications}

To reestablish the natural flow, reduce flood risks, and restore the ecological continuity, river managers are considering lowering or even suppressing the weirs. However, even if these restoration measures seem to be relevant over the long term, many hydromorphological and ecological effects might emerge, such as backward erosion, over-delivery of sediments to the downstream fluvial system, to name a few (Malavoi et al., 2011). Besides, due to mining activities during almost three decades (1941-1969) immediately upstream the LDG reach, there are still many excavations and waste on the former plot that could, in some instances, be dangerous from a human or environmental point of view. Today, these metallic residues (zinc, mercury, lead, arsenic) are suspected of accumulating in living beings (fish, mosses, invertebrates) or fixed in the fine fraction of the alluvial stock (sediments of the type: clay, silt). Most of these sediments are now suspected to be stored in the LDG, located approximately $5 \mathrm{~km}$ downstream from the former mining site. Thus, depending on which restoration measure is selected, this information must be considered knowing the risks of contamination of the downstream area.

A hydro-morphological 2D model was developed at the LDG reach scale to understand the different morphological processes within this channel and help river managers make an informed decision on the restoration of this reach.

\section{Model description}

The system TELEMAC-MASCARET is considered for the numerical simulations. TELEMAC-MASCARET is an opensource software package with numerous modules to compute free surface flows, sediment transport, swell, and water quality (Hervouet, 2003). Among these modules, we selected the ones related to hydrodynamic and morphodynamic processes: TELEMAC2D and SISYPHE.

In this section, the hydrodynamic module is introduced as well as its morphodynamic module SISYPHE. Then its application to the study area is presented. Finally, the model's performance will be assessed, and we will conclude on the difficulties encountered while performing the simulation on such complex morphology.

\subsection{Hydrodynamic module}

The hydrodynamic module, TELEMAC2D, solves Shallow Water Equations (SWE) simultaneously (de Saint-Venant, 1871) (Eq. 1).

$$
\left\{\begin{array}{l}
\partial_{t} h+\boldsymbol{u} \cdot \nabla(h)+h \nabla \cdot(\boldsymbol{u})=0 \\
\partial_{t} u+\boldsymbol{u} \cdot \nabla(u)=-g d_{x} z f-g S_{f, x}+h^{-1} \nabla \cdot\left(h v_{t} \nabla u\right) \\
\partial_{t} v+\boldsymbol{u} \cdot \nabla(v)=-g d_{y} z_{f}-f S_{f, y}+h^{-1} \nabla \cdot\left(h v_{t} \nabla v\right)
\end{array}\right.
$$

where $\mathrm{t}[\mathrm{s}]$ is the time, $\partial_{t}=\partial / \partial_{t}, \nabla=\left(\partial_{x}, \partial_{y}\right)$ is the gradient vector field, $g=9.81 \mathrm{~m} / \mathrm{s}^{2}$ the gravitational acceleration, $h[\mathrm{~m}]$ is the water depth, $\boldsymbol{u}=(u, v)[\mathrm{m} / \mathrm{s}]$ is the depth-averaged flow velocity vector with $u$ and $v[\mathrm{~m} / \mathrm{s}]$ the components along the longitudinal x-axis and transversal y-axix direction respectively, with $|\boldsymbol{u}|[\mathrm{m} / \mathrm{s}]$ the module of $\boldsymbol{u}$, and $v_{t}\left[\mathrm{~m}^{2} / \mathrm{s}\right]$ is the turbulent eddy viscosity term. 
The TELEMAC model treats turbulence from a diffusion term. Four options are available:

- the constant viscosity model. The associated coefficient represents molecular viscosity, turbulent viscosity and dispersion;

- the Elder model. This model takes into account the dispersion by assuming that the vertical profiles of the velocities are logarithmic;

- the k-Epsilon model. This model solves the transport equations for $\mathrm{k}$ (the turbulent energy) and Epsilon (turbulent dissipation). The latter is known to be more expensive in terms of computational time and requires a finer mesh compared to the other models;

- the Smagorinski model, which is generally used for maritime domains with large-scale fluctuation phenomena.

The four turbulence models were tested in the framework of this study.

\subsection{Sediment transport and bed evolution module}

The morphodynamic module is based on the Exner equation (Eq. 2) (Exner, 1920), which can be coupled with the equation of the hydrodynamic module:

$(1-n) \frac{\partial Z_{f}}{\partial t}+\nabla \cdot Q_{s}=0$

where $n$ is the non cohesive bed porosity [-], $Z_{f}[\mathrm{~m}]$ corresponds to the river bottom elevation, and $Q_{s}\left[\mathrm{~m}^{2} / s\right]$ the bedload rate per unit width. Further information on this module can be found in Tassi and Villaret (2014)).

\subsubsection{Friction laws}

Two friction laws were considered: the widely known Manning-Strickler (1923) formula (Eq. 4) and the Ferguson (2007) formula. The Ferguson (2007) friction law has been proposed to ensure the transition between a uniform profile related to relative shallow depths and larger relative depths, whereas the Manning-Strickler formulation is better suited for larger relative depths. This equation of Ferguson (2007) has been tested on a wide range of data and has proved to be efficient to cover all hydraulic configurations encountered from headwaters to lowland rivers. It is expressed as follows (Eq. 3):

$\frac{U}{\sqrt{g R_{h} S}}=\frac{2.5 \frac{R_{h}}{D_{84}}}{\sqrt{1+0.15\left(\frac{R_{h}}{D_{84}}\right)^{5 / 3}}}$

with $S[\mathrm{~m} / \mathrm{m}]$ the river bed slope, $D_{84}[\mathrm{~m}]$ diameter for which $84 \%$ of sediments are finer, $R_{h}(\mathrm{~m})$ the hydraulic radius, $U$ $\left[m s^{-1}\right]$ the mean flow velocity, and $g\left[\mathrm{~ms}^{-2}\right]$ the gravitational acceleration.

The friction coefficient for the Ferguson (2007) law is the $D_{84}$.

The Manning-Strickler friction law can be expressed as follows (Eq. 4):

$U=K R_{h}^{3 / 2} S^{1 / 2}$ 
with $U\left[\mathrm{~ms}^{-1}\right]$ the mean flow velocity, $S[\mathrm{~m} / \mathrm{m}]$ the river bed slope, $R_{h}[\mathrm{~m}]$ the hydraulic radius, and $K\left[\mathrm{~m}^{1 / 3} s^{-1}\right]$ the friction coefficient.

\subsubsection{Bedload transport formulas}

The morphodynamic module SISYPHE considers several semi-empirical sediment transport formulas (Tassi and Villaret, 2014). The module also offers the possibility to code a formula, if it is not included. In our case, we considered two bedload transport formulas: the Meyer-Peter and Müller (1948) formula (Eq. 5) and the Recking (2013b) formula (Eq. 6).

The Meyer-Peter-Müller formula:

The Meyer-Peter-Müller equation is a threshold equation and its original formulation considers a critical Shields parameter equal to 0.047. A sensitivity analysis was performed on this parameter as its value can highly influence sediment transport. The formula is written as follows (Eq. 5):

$\Phi=8\left[\left(\frac{K^{\prime}}{K}\right)^{3 / 2} \tau^{*}-0.047\right]^{3 / 2}$

with $K / K^{\prime}$ the ratio between the flow Strickler coefficient $K$ and the grain roughness coefficient $K^{\prime}$. This term makes it possible to correct the total constraint in order to take into account only the grain shear stress. $K$ is given by $K=\frac{U}{S^{1 / 2} R^{2 / 3}}$ and the grain roughness coefficient is estimated as a function of the granulometry $K^{\prime}=\frac{1}{n}=\frac{26}{D_{*}^{1 / 6}}$, with $D_{*}$ the diameter of grain class $i[\mathrm{~m}]$.

This formulation is primarily based of laboratory experimentation with uniform and non-uniform sediments. It is one of

the most used formulas when it comes to studying a river or a laboratory case study with a heterogeneous grain-size. This characteristic makes it adapted to the LDG reach. However, the fact that it is only calibrated on laboratory measures can lead to non realistic results with in-situ input data. Besides, as it is a threshold formula, its performance may be poor around the threshold.

The Recking formula:

195 This non-threshold formula results from the work of Recking (2010, 2013b); Recking et al. (2016) and can be written as follows (Eq. 6):

$q_{b}^{*}=\frac{q_{b}}{\rho_{s} \sqrt{g(s-1) D_{84}^{3}}}=\frac{14 \tau_{84}^{* 2.5}}{1+\left(\frac{\tau_{m}^{*}}{\tau_{84}^{*}}\right)^{4}}$

$q_{b}\left[\mathrm{kgs}^{-1} \mathrm{~m}^{-1}\right]$ is the unit bedload discharge per unit of width, $s=\rho_{s} / \rho$ is the sediment density, and $g$ the gravity acceleration. The parameter $\tau_{m}^{*}$ is a mobility term that defines the transition between partial transport and full mobility (Recking et al., 2016).

The following formulation was developed for the riffle pools and alternate bars (Eq. 7):

$\tau_{m}^{*}=(5 S+0.06)\left(\frac{D_{84}}{D_{50}}\right)^{4.4 \sqrt{S}-1.5}$

Equation 8 can be used for other morphologies:

$\tau_{m}^{*}=1.5 S^{0.75}$ 
https://doi.org/10.5194/esurf-2021-91

Preprint. Discussion started: 26 January 2022

(c) Author(s) 2022. CC BY 4.0 License.

(c) (i)

The main advantages of this formulation are that (Gonzales De Linares et al., 2020):

- it considers partial transport ;

- it has been developed based on field data, which makes it adapted to cross-section averaged calculations ;

- it has been validated with a wide data set for different independent watercourses ;

- it is adapted to mountain and Piedmont rivers with steep slopes and coarse grain-size.

The Recking formula was coded in the subroutine "qsform.f" as it was not available among the proposed sediment transport equation in the SISYPHE module.

\section{Method}

A model was developed at the LDG's reach scale to reproduce the hydrodynamic and morphodynamic processes that occured during the 10-year return flood of June 2018. In fact, it was the only event for which we had the before and after topobathymetric data, necessary to check the model's ability to reproduce the observed morphological modifications. The followed methodology considered field data collection for the model's development and performance evaluation, the model generation, the selection of a relevant hydrodynamic model, after which a clear hydrodynamic calibration with a fixed bed to select the riverbed roughness was performed, to finally run the morphodynamic model with the two different bedload transport formulas.

\subsection{Input data}

\subsubsection{Field data}

The model starts at the junction of the "Gave de Gavarnie" and the "Gave de Cauterets" and extends up to the weir of the municipality of "Agos-Vidalos" (Fig. 4).

The available field data for the model's implementation are:

- a LiDAR DEM surveyed in 2016 ;

- a LiDAR DEM surveyed in 2019 a few months after the flood of June 2018 ;

- dredging data (SHEM) provided by the former operators of the weirs. This data gives information on the possible bedload fraction that fills the LDG ;

- grain-size data, collected on the ground over four sediment bars along the considered river reach. The hydromorphodynamic computations considered only the $D_{50}=50 \mathrm{~mm}$ for the MPM formula and the $D_{84}=163 \mathrm{~mm}$ for the Recking formula. These data were collected thanks to the Wolman sampling technique (Wolman, 1954), upstream the Beaucens weir ; 


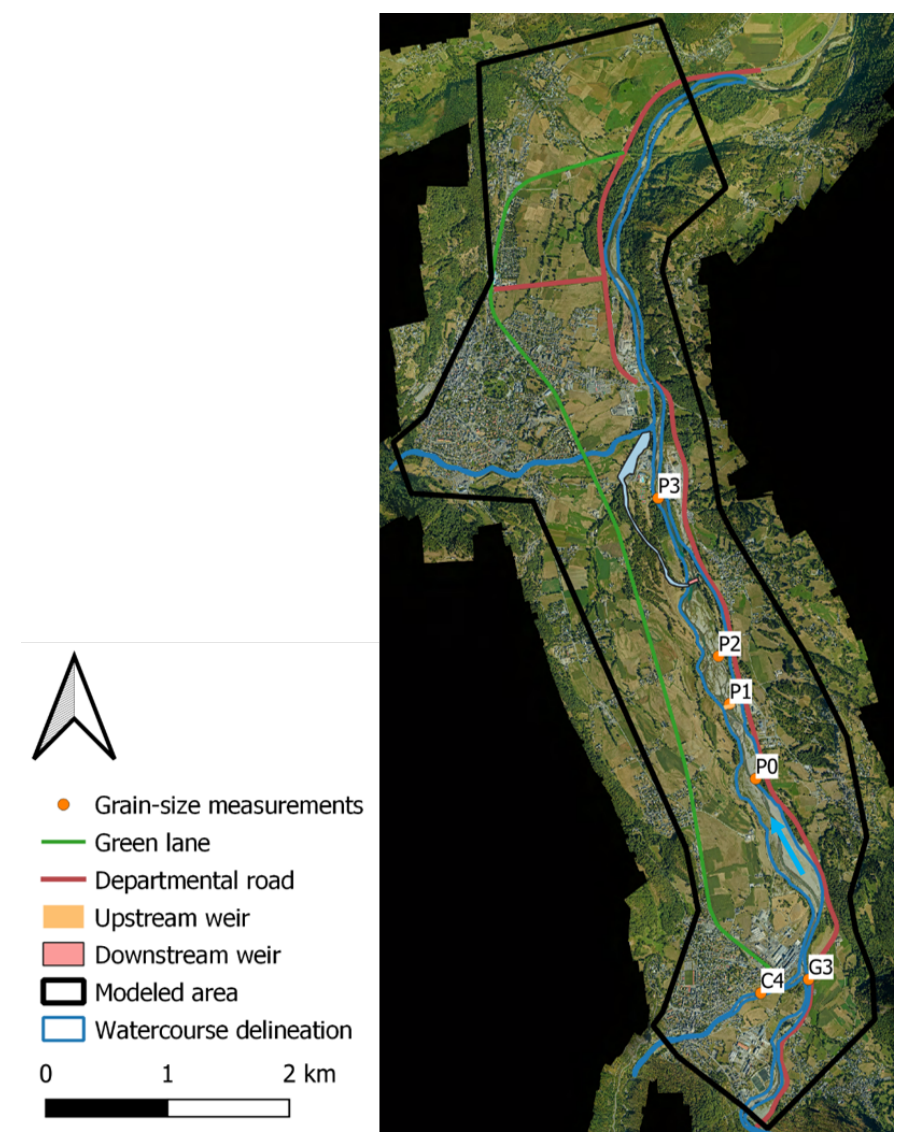

Figure 4. Overview of the considered area for hydromorphological modeling and identification of the different areas of interest

- hydraulic data, representing water levels surveyed during the recession time of the 2018 flood event.

It is common to use sediment traps dredging data to estimate event-driven sediment transport in mountainous catchments as its measurement can be complicated in such flow conditions (Liébault et al., 2010). It appears that the LDG seems to have similar behaviour, even if it was not designed for this purpose. However, the recorded volumes represent both very fine sediments probably transported by suspension and very coarse sediment via bedload transport. To discriminate bedload from suspended load, coarse sediment dredging data over 11 years were collected upstream the first weir. The bedload volume is thus estimated to represent between 8 and $16 \%$ of the total transport, which is coherent with the feedback from the literature on similar configurations (Misset et al., 2020). This range of variation will be considered to compare simulated deposited volumes to observed ones. 
https://doi.org/10.5194/esurf-2021-91

Preprint. Discussion started: 26 January 2022

(c) Author(s) 2022. CC BY 4.0 License.

(c) (i)

\subsubsection{Input hydrograph}

The input discharges were generated by the physically based distributed hydrological model MARINE (Roux et al., 2011; Douinot et al., 2018; Roux et al., 2020) developed at the catchment scale. The model is structured in three main modules. The first module separates precipitation into surface runoff and infiltration; the second represents subsurface runoff, and the last one represents surface runoff on slopes and in the drainage network. This last module is based on a transfer function that allows the routing of excess precipitation to the watershed outlet through the use of the kinematic wave approximation of the Barré-de-Saint-Venant equations. The spatial discretization of the catchment area is done using the grid resolution of the DEM.

The MARINE model is capable of simulating flood hydrographs at any point in the drainage network which is a real advantage in order to have an accurate approximation of the inputs to the Lac des Gaves system. Thus, three hydrographs were extracted for the big mesh (Fig. 5, left) for the three tributaries (the Gave de Cauterets, the Gave de Gavarnie and the Gave d'Azun) and one for the smaller mesh (Fig. 5, right). The details about the two different meshes are presented in the following section.

\subsection{Model setup}

\subsubsection{Mesh generation}

We built unstructured triangulated meshes using the software BlueKenue ${ }^{2}$. Sediment transport modelling is very sensitive to mesh size. Thus, two approached were tackled to create the meshes (Fig. 5):

- an eight kilometers long unstructured triangulated mesh that covers the whole study area (355 062 elements) was built. The mesh size is $3 \mathrm{~m}$ within the watercourse, $2 \mathrm{~m}$ in the fishery water intake area and $100 \mathrm{~m}$ in the floodplain ;

- a finer two kilometers long mesh in the LDG area around the two weirs (201569 elements). The mesh size for this smaller domain is $1 \mathrm{~m}$ in the riverbed, $2 \mathrm{~m}$ in the fishery water intake and $20 \mathrm{~m}$ in the floodplain.

The small mesh was considered to perform a less time consuming fine analysis of the sediment transport behaviour around the area of interest: the LDG between the two weirs. The obtained results with this small mesh allowed us to pick the best performing parameters for the whole domain with which we only simulated restoration scenarios, resulting in a substantial saving of time.

To represent the anthropogenic structures along the river, fixed embankments, weirs and rip-raps, were considered as non erodible (blue in Fig. 5) in the context of sediment transport computations.

\subsubsection{Boundary conditions}

For the mesh representing the entire study area, four boundary conditions were defined. Upstream, discharges are set as an input for the "Gave de Gavarnie", "Gave de Cauterets" branches and the "Gave d'Azun" branch downstream the LDG. The

\footnotetext{
${ }^{2}$ http ://www.nrc-cnrc.gc.ca/fra/solutions/consultatifs/blue kenue index.html
} 
https://doi.org/10.5194/esurf-2021-91

Preprint. Discussion started: 26 January 2022

(c) Author(s) 2022. CC BY 4.0 License.

(c) (i)

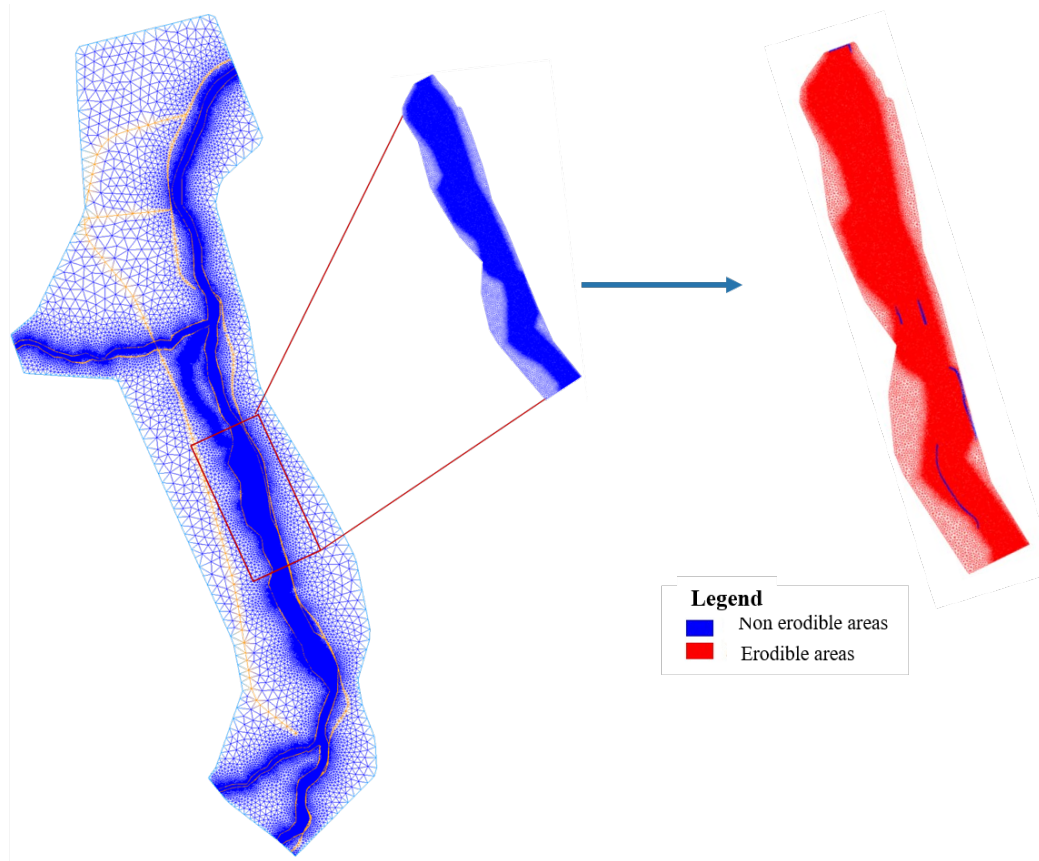

Figure 5. Considered meshes for the hydromorphological modelling. The orange lines represent soft-lines corresponding to roads or river banks where we force the mesher to pass through

downstream boundary condition is a free surface elevation determined by a rating curve calculated with a weir law (Eq. 9) respecting the characteristic of the "Agos-Vidalos" weir:

$Q=L \times \mu \times \sqrt{2 g} \times\left(h-Z_{w e i r}\right)^{(3 / 2)}$

with $L[\mathrm{~m}]$ the spillway width, $g\left[\mathrm{~m} . \mathrm{s}^{-2}\right]$ the gravitation acceleration, $h$ [m asl] the free surface elevation, and $Z_{\text {weir }}[\mathrm{m}$ asl] the weir elevation.

As for the sediment transport boundary conditions, we first attempted to prescribe solid discharges estimated thanks to the 2752018 hydrograph and the Recking (2013a) formula as no bedload measurements were available for this event. Unfortunately, this generated many instabilities around the upstream boundary. To overcome this limitation, a morphological equilibrium condition is set at the inlet (Tassi and Villaret, 2014). The particularity of this boundary condition is that it delivers sufficient bedload at the model inlet to keep the riverbed elevation at the inlet cross-section constant in time.

For the smaller mesh, two boundary conditions were defined. The 2018 flow hydrograph for the "Gave de Pau" river is set as an input upstream. The downstream boundary condition is a free surface elevation estimated with the same weir law presented above (Eq. 9) respecting this time the characteristic of the "Préchac" weir. 
https://doi.org/10.5194/esurf-2021-91

Preprint. Discussion started: 26 January 2022

(c) Author(s) 2022. CC BY 4.0 License.

\subsection{Calibration strategy}

\subsubsection{Hydrodynamic model}

In a classical way, hydrodynamic calculations are first carried out. To calibrate the hydrodynamic, simulations on a steady state were performed for a discharge of $58.4 \mathrm{~m}^{3} / \mathrm{s}$ measured on July 9, 2018 and represented in Fig. 6.

In the TELEMAC-MASCARET system, two categories of parameters can be adjusted: the numerical parameters and the physical ones (De Linares, 2007). In our case, we focused on the physical one with a variation of Strickler friction coefficient from $20 \mathrm{~m}^{1 / 3} / \mathrm{s}$ to $60 \mathrm{~m}^{1 / 3} / \mathrm{s}$. Water surface measurements along the river are used to quantify the simulations' accuracy. Model's accuracy is evaluated using the Root Mean Square Error (RMSE).

The best results were obtained with the $K=30 \mathrm{~m}^{1 / 3} / \mathrm{s}$ friction coefficient for the constant viscosity turbulence model (Fig. 6). The LDG area is well represented as the errors do not exceed $20 \mathrm{~cm}$ between the two weirs and the RMSE value obtained for this simulation is 0.31 .

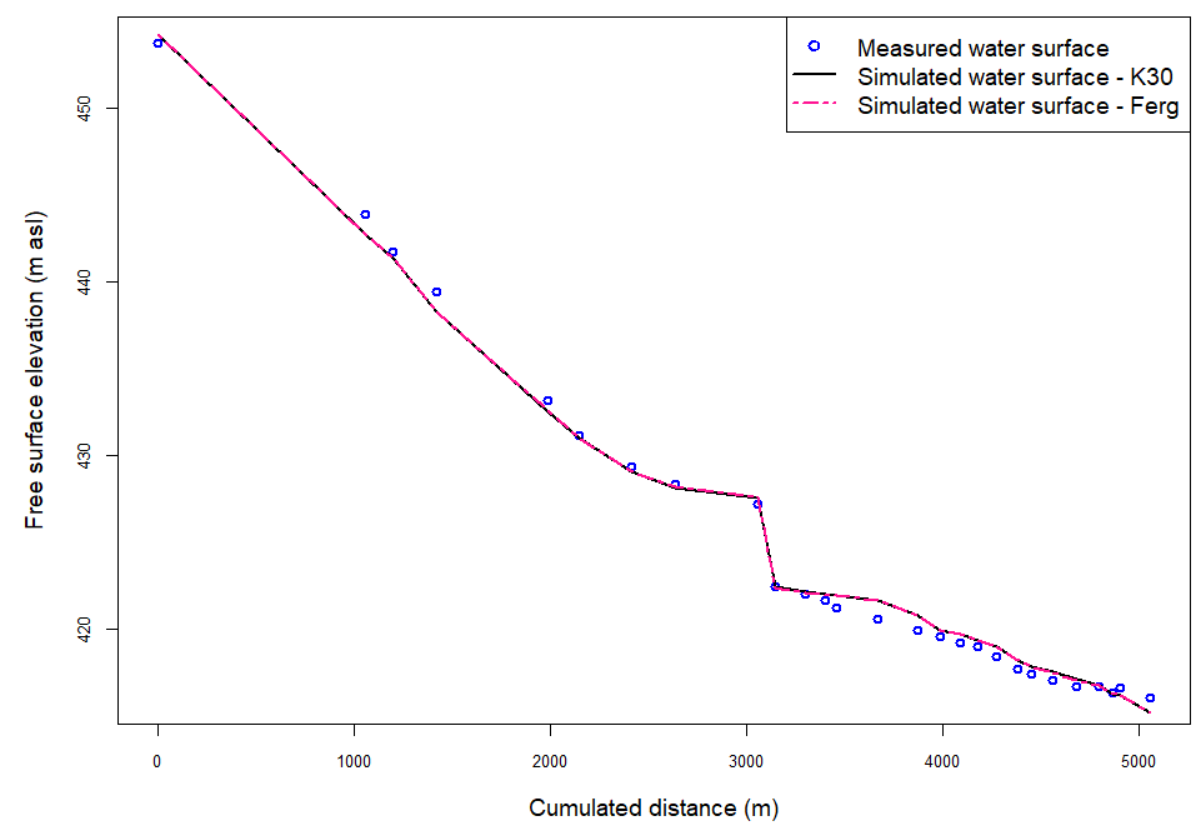

Figure 6. Longitudinal profile of observed and simulated water surfaces corresponding to a discharge of $58.4 \mathrm{~m}^{3} / \mathrm{s}$ measured the $09 / 07 / 2018$ - K30 (resp. Ferg): simulation with Strickler (resp. Ferguson) friction law 
https://doi.org/10.5194/esurf-2021-91

Preprint. Discussion started: 26 January 2022

(c) Author(s) 2022. CC BY 4.0 License.

(c) (i)

\subsubsection{Hydro-morphodynamic model}

The hydro-morphodynamic simulations were based on the flood event of 2018 that we assumed responsible for the visible morphological changes between the two topographic campaigns of 2016 and 2019. Unfortunately, there are no other experimental data on the studied area to consider a validation of the developed model. Further topo-bathymetric surveys are needed to assess the validity of the developed model.

First, the friction coefficient and the turbulence model selected during the hydrodynamic calibration process were used for the first hydro-morphodynamic simulations. Then other simulations for the two sediment transport (MPM and Recking) and friction formulas (Ferguson and Strickler) were performed. The specific parameters of each sediment transport formula (Shields number, MPM coefficient, slope effect, etc.) were tested afterwards to analyse their influence on the performance of the simulations.

\subsection{Performance evaluation}

\subsubsection{General comparison of erosion and deposition areas}

The model's qualitative performance evaluation was first done by visually comparing the simulated geomorphological evolution maps to the observed field evolution, before and after the flood of June 2018. This allows a qualitative evaluation of the model's capacity to reproduce the spatial variability of the processes (erosion and deposition) and to locate possible aberrations.

Longitudinal profiles and cross-sections where significant morphodynamic processes occurred were also compared to acquire a more refined vision of the evolution at the local scale. However, in braided rivers, as in the "Gave de Pau", a significant variability is observed between two measurements knowing channel migration phenomena.

\subsubsection{The Brier Skill Score}

The model's calibration requires a considerable amount of computations where different parameters are modified. Identifying rapidly the best performing with a cost function can thus be time saving. The selected cost function to do this is the Brier Skill Score (BSS). It was developed initially for the assessment of meteorological model's performance and uses a baseline prediction to quantify the model's new prediction skill. Furthermore, during the last decades, many hydromorphological studies considered it to evaluate the model's skill to simulate the sediment erosion and deposition processes along the whole domain (Aguirre et al., 2020; De Linares, 2007; Sutherland et al., 2004). It can be expressed as follows (Eq. 10):

$B S S=1-\frac{\frac{1}{N} \sum_{i}^{N}\left(y_{i}-x_{i}\right)^{2}}{\frac{1}{N} \sum_{i}^{N}\left(b_{i}-x_{i}\right)^{2}}$

with $N$ the number of measurement points, $b_{i}$ baseline, here we use initial river bed elevation (DEM of 2016), $x_{i}$ observed river bed elevation (DEM of 2019) and $y_{i}$ the simulated river bed elevation. Table 1 shows the recommended model performance classification for the BSS. 
https://doi.org/10.5194/esurf-2021-91

Preprint. Discussion started: 26 January 2022

(c) Author(s) 2022. CC BY 4.0 License.

(c) (i)

Table 1. Classification of BSS values for model performance evaluation (Aguirre et al., 2020)

\begin{tabular}{cc}
\hline $\begin{array}{c}\text { Performance of the } \\
\text { simulation }\end{array}$ & BSS Value \\
\hline Excellent & $1.0-0.5$ \\
Good & $0.5-0.2$ \\
Reasonable & $0.2-0.1$ \\
Poor & $0.1-0.0$ \\
Bad & $<0.0$ \\
\hline
\end{tabular}

One of the major advantages of considering the BSS for the hydromorphological model's performance is that its value is not impacted if measurement points did not present any evolution. The number of considered grid points should only have little influence on the BSS value.

\subsubsection{Comparison of the deposited volumes}

Using a cost function to evaluate a hydromorphological model's performance with a braided morphology can be quite pessimistic. To date, numerical models cannot predict channel migration processes that occur in braided rivers. These phenomena are uncertain and random. A modeler should thus not expect the model to predict channel migration accurately during a flood.

As the issue here is the filling of the LDG and the high amount of sediments that might be delivered to the downstream system if the weirs are levelled, the comparison of the simulated deposited volumes with the field data appears to be a relevant model's performance indicator. Field erosion and deposition areas were estimated through topo-bathymetric differencing between two LiDAR DEMs surveyed in 2016 and 2019 (Fig. 7). The 10-year return period flood of June 2018 is considered the only morphodynamic flood that occurred during this period.

\section{Results and discussion}

The TELEMAC-MASCARET modelling system can run in parallel mode using domain decomposition and MPI based codes. The calibration scenarios have been carried out on a Linux server over 16 processors at the Institut de Mécanique des Fluides de Toulouse (IMFT).

The performance of the two friction laws and the two bedload formulas was assessed with the three performance indicators: longitudinal profiles and cross-sections comparison, BSS scores along with the whole domain and the comparison of the deposited volumes is also considered. 


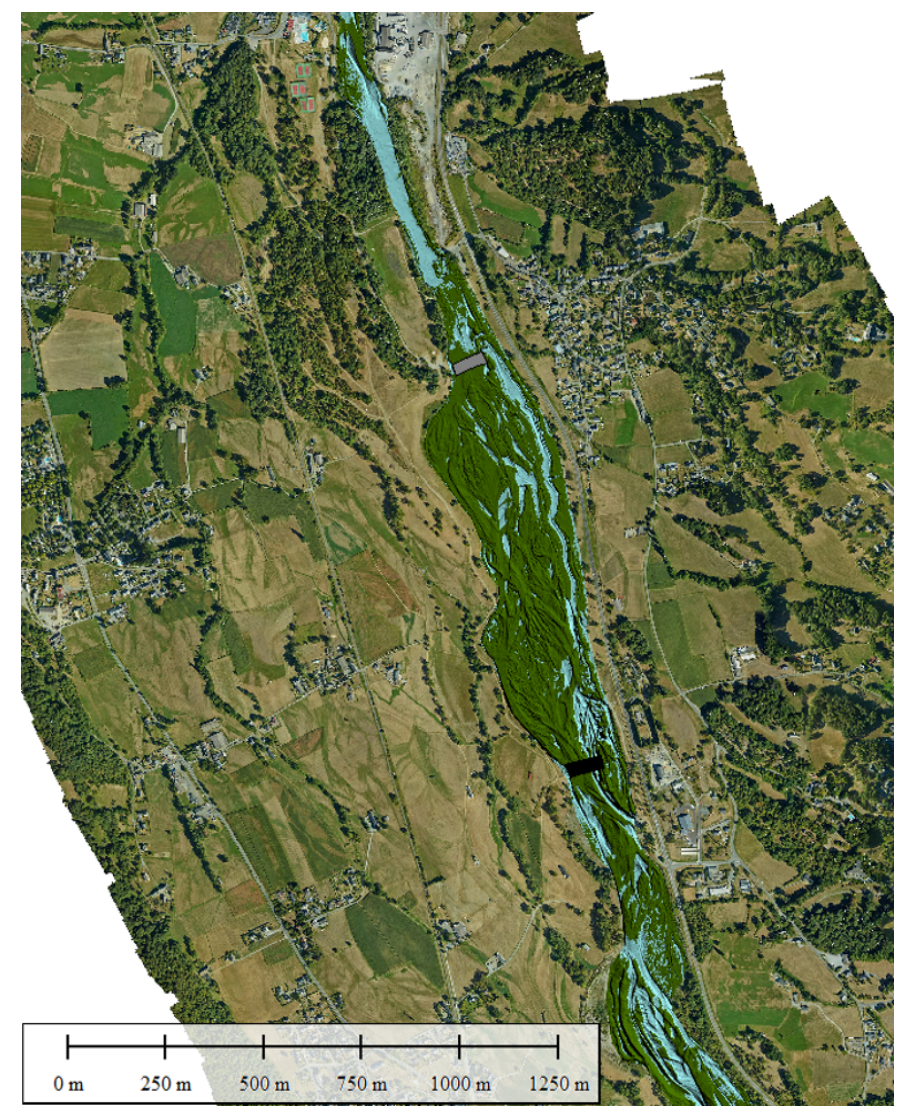

Figure 7. Eroded (light blue) and deposited (dark green) areas in the LDG reach. The upstream weir is represented in black and the downstream weir in grey. This figure illustrates the filling of the LDG as almost all its surface represents deposited materials

\subsection{General visual comparison of eroded and deposited areas}

The simulated results are compared only within the intersection of areas that were emerged during the two LiDAR campaigns (2016-2019) as this technique does not collect submerged bathymetric data. In general, the model seems to correctly represent the filling tendency of the LDG as a deposition front can clearly be observed, which is coherent with what is observed in the field (Fig. 8). The simulated evolution shows that the selection of a friction law has more impact on the results than the sediment transport equation. In fact, for both sediment transport formulas, the Strickler friction law tends to overestimate erosion and deposition processes within the LDG reach, whereas they seem to be minimised with the Ferguson friction law (Fig. 8 and 9). This highlights the importance of the friction law as it conditions the shear stress calculations' results and thus bedload transport. Friction laws are equations that usually link flow velocity to flow depth (Rickenmann and Recking, 2011). The Manning-Strickler formula is particularly suited for high submersion flows (Ferguson, 2007; Rickenmann and Recking, 2011) whereas the Ferguson friction law is known to have the best performances from low to high submergence (Rickenmann 
and Recking, 2011) which is probably more suited to our case study. This explains why sediment depositions and erosions appear to be overestimated with the Strickler formula. The Ferguson friction law seems thus better suited to the complexity of the processes that occur within the LDG.

If we compare the obtained results with the Ferguson friction law for the two bedload transport formulas, the simulations with the MPM formula tend to predict higher sediment deposition and erosion amounts. As it is a threshold formula, the results below or around the critical shear stress can be poor because of a zero prediction or an overestimation of sediment transport. This formula is considered efficient when $\tau_{84} / \tau_{c 84}>2$ and thus for rather strong flow conditions (Recking et al., 2012). In our case, as we consider the whole 2018 hydrograph (10 days), we are not always in these conditions. Hence, the observed over-estimations can be due to fluctuations around the threshold during the 2018 flood event.

The morphodynamics around the upstream weir (Fig. 9) are more complex. During the 2018 flood event, two main river branches were created (left and right bank) with very strong erosions around the right bank and considerable depositions elsewhere. The comparison with the experimental evolution has to be taken carefully as the bathymetry under the water surface cannot be captured by the LiDAR technique. However, as the two measurement campaigns were conducted in severe low-water seasons, we can thus estimate that these uncertainties are reduced. Figure 9 shows that the two sediment transport formulas can reproduce the observed erosion processes around the right bank but to a lesser extent. The strong erosion observed in the right bank during the flood (pink in Fig. 9a) is actually due to the disappearance of a river protection that has been washed out by the flood. It seems like the model is not able to reproduce this phenomenon. In fact, the maximum simulated water extent for both sediment transport formulas (Fig. 9b and 9c) does not reach this area which explains why this extreme erosion process is not reproduced. However, the MPM sediment transport formula tends to estimate stronger erosion and deposition processes compared to the Recking formula that seems to minimise them.

Finally, for the two sediment transport formulas, the model predicts that all the depositions only occur within the first half of the LDG. The model estimates that downstream this sediment deposition front, no or very little evolution occurs. This can be due to the fact that many factors are not considered in the model such as the consideration of the whole grain-size distribution. Besides, the downstream part of the LDG is mainly composed of very fine sediments. The morphological evolution within this section is thus, for the most part, due to suspended load, not considered in our model.

\subsection{Longitudinal profiles and cross-section comparison}

Further quantitative investigations were done by comparing longitudinal profiles for both sediment transport formulas and friction laws. For the MPM formula, longitudinal profiles comparison confirms that the Strickler friction law tends to overestimate bedload depositions within the LDG (Fig. 10). The same conclusions can be drawn with the Recking formula and Strickler friction law (Fig. 11). It seems thus that the Ferguson law is the one providing the most realistic results for both bedload formulas, which is coherent with the visual interpretation made in section 5.1.

The longitudinal profiles comparison for both bedload transport formulas with the Ferguson friction law (Fig. 12) shows that MPM formula tends to overestimate sediment depositions within the first half of the LDG (950-1400 m) compared to the Recking formula. However, the sediment deposition front progression seems to be more accurately simulated with the MPM 
https://doi.org/10.5194/esurf-2021-91

Preprint. Discussion started: 26 January 2022

(c) Author(s) 2022. CC BY 4.0 License.

(c) (i)

(a)

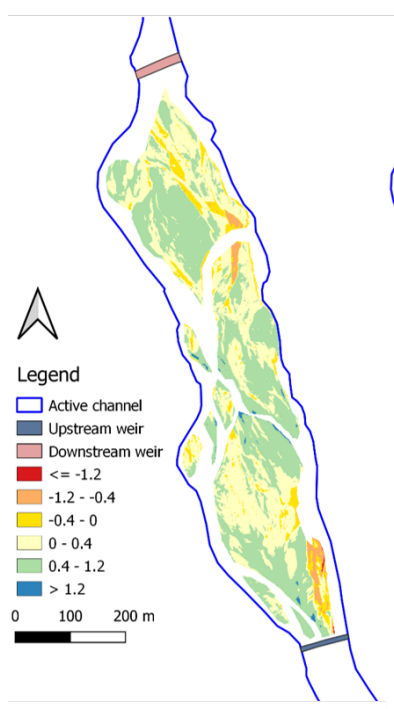

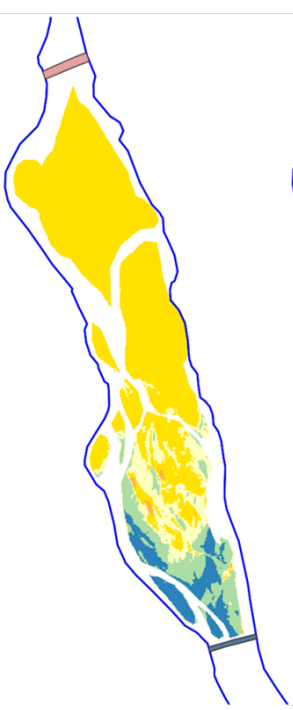

(d)

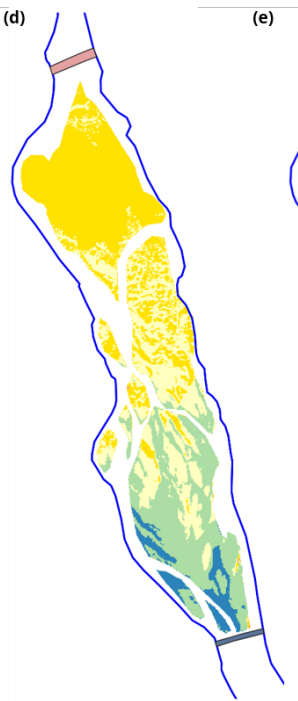

Earth Surface

Dynamics

Discussions (c)
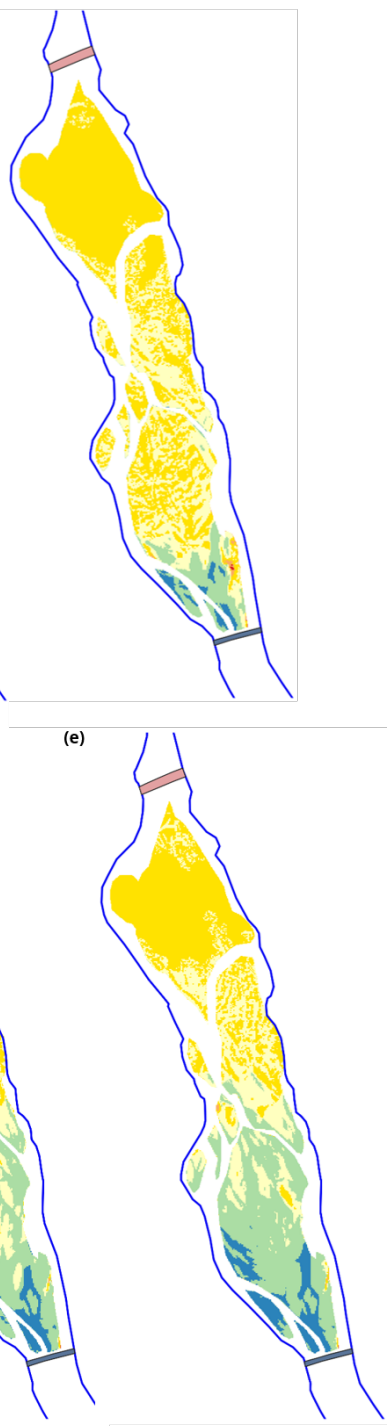

Figure 8. Comparison of the simulated evolution with the two bedload formulas (MPM and Recking) and the two friction laws (Strickler and Ferguson). (a) is the 2016-2019 topo-bathymetric differencing; the simulated evolutions are represented with (b) the MPM formula and the Ferguson friction law; $(\boldsymbol{c})$ the Recking Formula and the Ferguson friction law; $(\boldsymbol{d})$ the MPM formula with the Strickler friction law and $(\boldsymbol{e})$ the Recking formula with the Strickler friction law. 
https://doi.org/10.5194/esurf-2021-91

Preprint. Discussion started: 26 January 2022

(C) Author(s) 2022. CC BY 4.0 License.

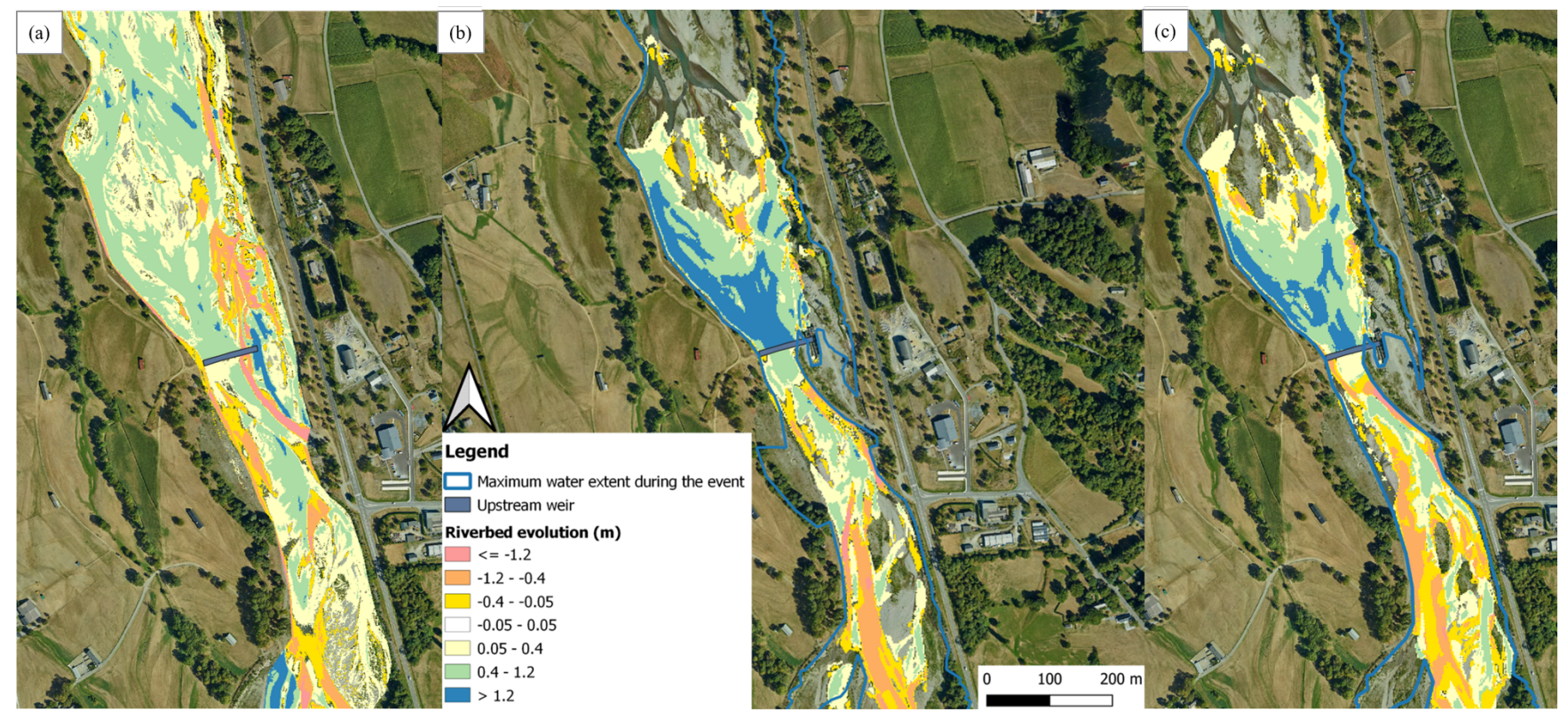

Figure 9. Channel evolution around the Beaucens weir. $(\boldsymbol{a})$ is the experimental evolution estimated through the difference between the 2016 and the 2019 topography; $(\boldsymbol{b})$ is the evolution estimated with the MPM sediment transport equation and the Ferguson friction law and (c) is the simulated evolution with the Recking sediment transport formula and the Ferguson friction law.

formula. Visually speaking, the simulated long profile with the Recking formula seems to be closer to the observed evolution. This is confirmed by the score of this simulation (BSS $=-0.01$ ) calculated over the long profile, whereas the MPM formula has a score of -0.3. As we can see, both simulations seem to perform poorly according to the BSS criteria only. This questions the relevance of this criteria for complex morphologies such as the braided LDG reach.

The evaluation of the model's performance over the cross sections confirms this statement (Fig. 13). Figure 13 shows that the model experiences difficulties in reproducing the different channels forming the braided morphology of the LDG reach. Strong erosions are observed for both formulas upstream the Beaucens weir within the main channel, which is not coherent with the observations on the ground. However, this comparison can be biased by the fact that we are manipulating LiDAR data, not taking into account the bathymetry below the water surface. For the upstream cross-section the two bedload transport formula perform poorly with a BSS of -0.04 for the MPM formula and -0.06 for the Recking formula. The comparison of the cross-sections downstream the weir shows that the Recking formula seems to have a better performance $(\mathrm{BSS}=0.35)$ compared to the MPM sediment transport formula $(\mathrm{BSS}=-1.2)$ that overestimates sediment depositions within the lake.

Finally, this topographic examination questions the classical performance analysis methods for morphodynamic models. Knowing the multiple variabilities in a mountain braided watercourse, performance criteria combined with local altimetric analysis might be too strict and incomplete to assess the ability of the model to reproduce the mobilised sediment volumes over a flood event. As the aim is to give the local elected representatives indications regarding possible sustainable restoration 

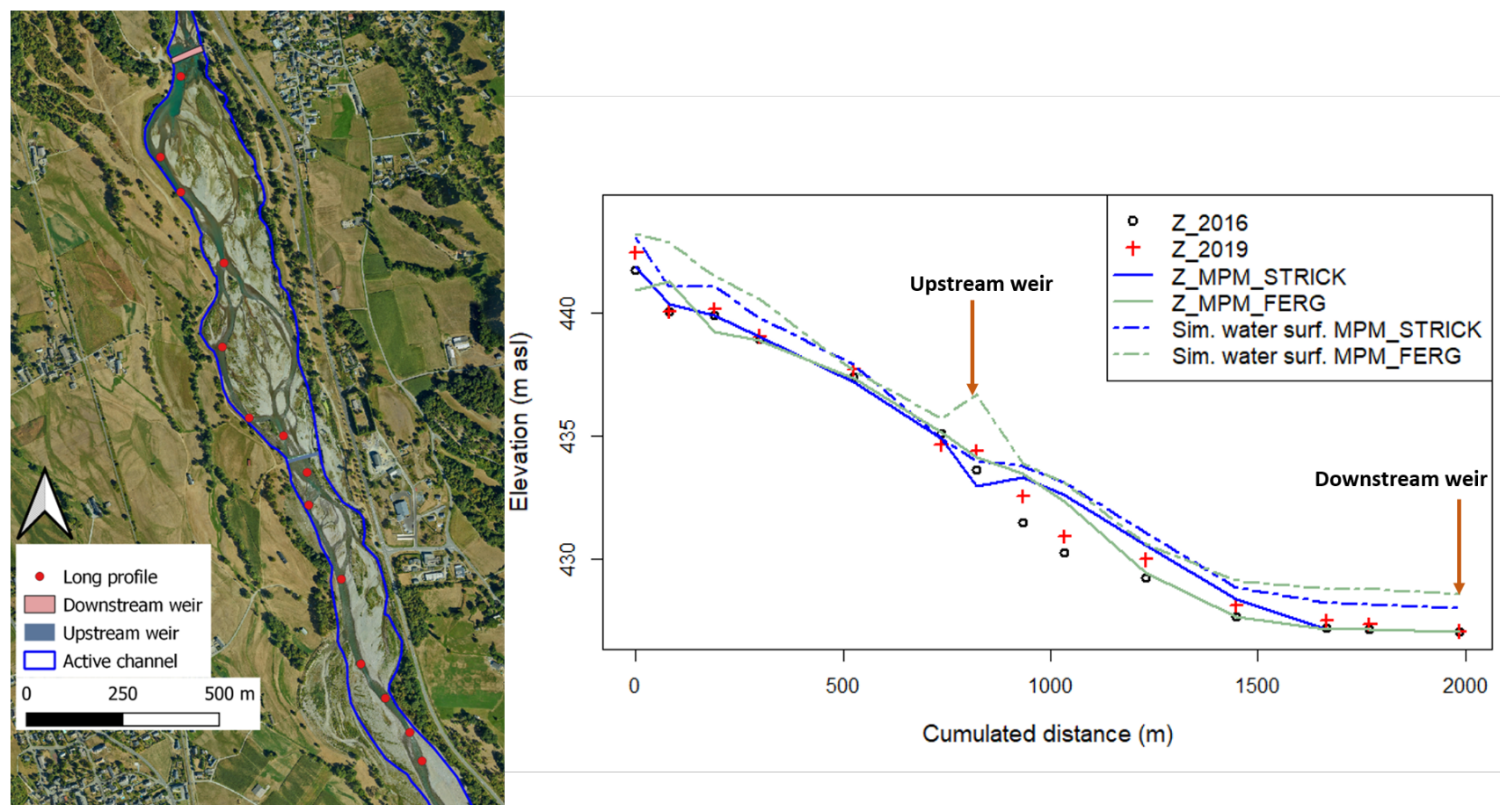

Figure 10. Simulated longitudinal profiles (solid lines) and maximum simulated water surface (dashed lines) comparison for the MPM formula and the two considered friction laws: STRICK for Strickler friction law, FERG for the Ferguson friction formula - Z_2016: DEM of 2016, Z_2019: DEM of 2019

scenarios, a volumetric analysis can provide valuable additional insights as it gives information on the possible volumes that might end up downstream if a weir lowering/removal solution is considered.

\subsection{Comparison of deposited volumes}

To compare the simulated deposited volumes to the ones observed in the field, the score $r=V_{\text {scal }} / V_{\text {smeas }}$, with $V_{\text {scal }}\left[\mathrm{m}^{3}\right]$ the simulated deposited volume and $V_{\text {smeas }}\left[\mathrm{m}^{3}\right]$ the measured deposited volume, was calculated between the two weirs (Table 2). When $r>1$, this means that we overestimate sediment depositions within the LDG, when $r<1$ it is the opposite: we tend to underestimate sediment deposition. The deposition phenomenon within the LDG is one of the most important processes to reproduce as it represents the potential volumes that might be mobilised if the weir lowering/removal restoration measure is considered.

The reconstruction of the filling of the lake through different periods has allowed the collection of interesting data that provides annual trends of material input. These results are derived from an analysis of bathymetric profiles from which the volumes were extracted. For the flood of 2018, a total (bedload and suspension) sediment deposition volume of $81220 \mathrm{~m}^{3}$ was estimated. In order to distinguish the bedload phenomenon and as our model only considers this process, dredging data were 


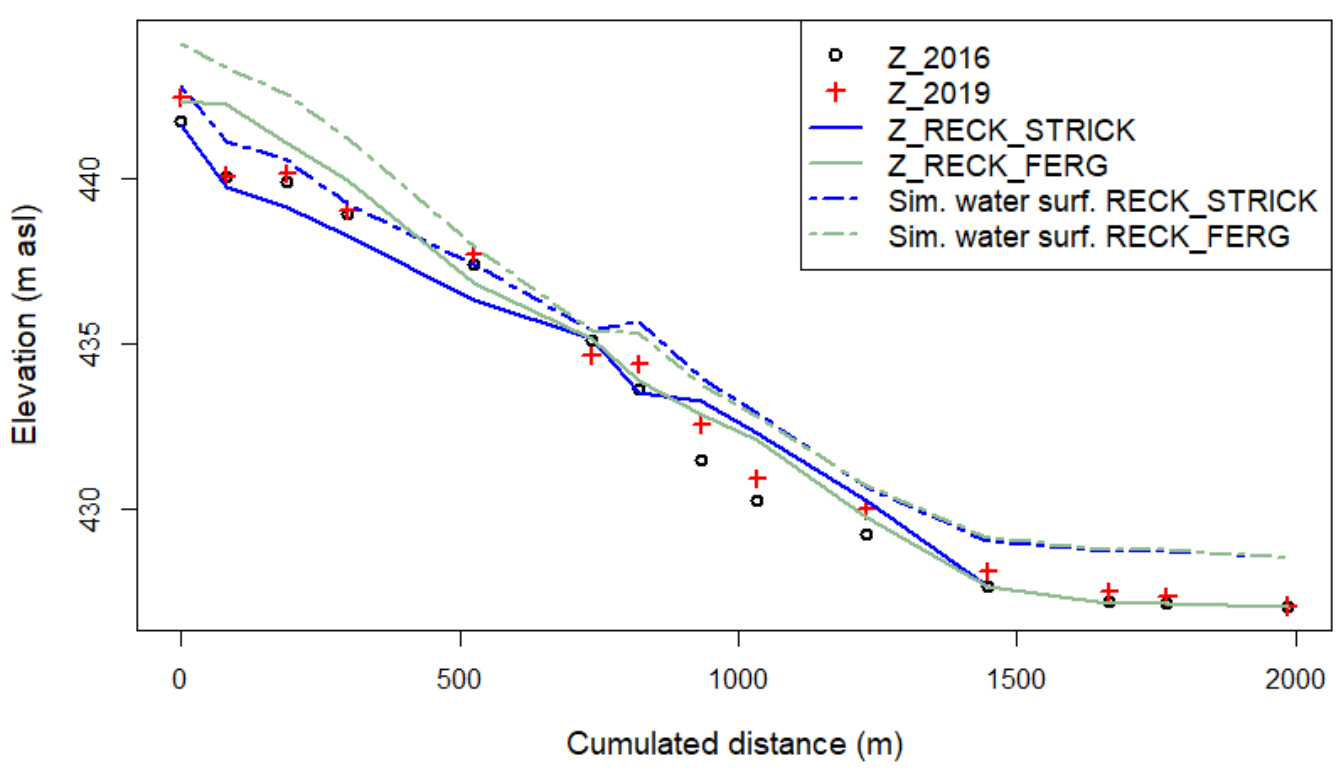

Figure 11. Simulated longitudinal profiles (solid lines) and maximum simulated water surface (dashed lines) comparison for the Recking formula and the two considered friction laws: STRICK for Strickler friction law, FERG for the Ferguson friction formula - Z_2016: DEM of 2016, Z_2019: DEM of 2019

415 collected for approximately ten years. These data allowed us to estimate the fraction of bedload of the total sediment transport. This fraction is estimated to be between 8 and $16 \%$ of the total transport, representing the lower and upper uncertainty interval limits.

As mentioned above, the model only considers bedload transport. Hence, the score calculation was performed on the fraction of sediments estimated to be deposited via a bedload transport process. Generally speaking, the model seems to simulate sediment depositions close to the upper interval limit (16\% of the total deposited volume observed including both suspension and bedload transport). The best results $(r=1.53)$ seem to be obtained with the combination of the Recking bedload transport formula and the Ferguson friction law, which is coherent with the interpretations made above with the longitudinal profiles comparison. The MPM formula tends to overestimate the deposited volumes; however, acceptable results were obtained with the Ferguson friction law $(r=2.44)$. This supports the fact that Ferguson friction formula seems to be the most suitable one for the LDG reach. 
https://doi.org/10.5194/esurf-2021-91

Preprint. Discussion started: 26 January 2022

(c) Author(s) 2022. CC BY 4.0 License.

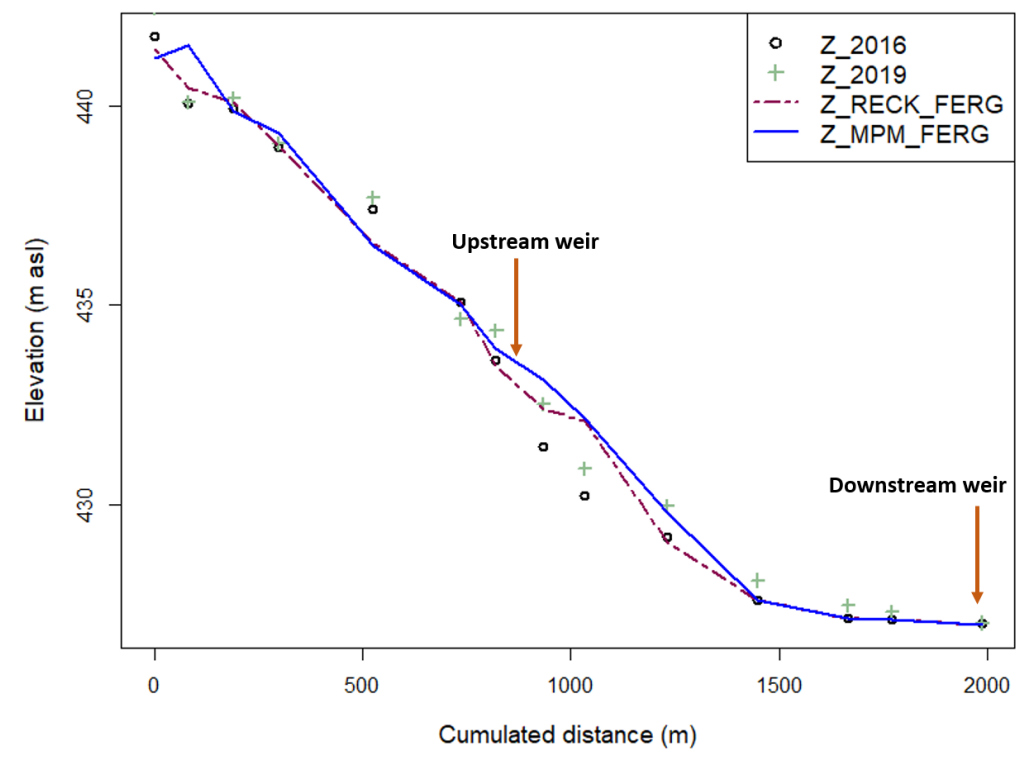

Figure 12. Simulated longitudinal profiles comparison for the Recking and the MPM bedload formulas and Ferguson friction law - Z_2016: DEM of 2016,Z_2019: DEM of 2019

Table 2. Comparison of simulated deposited volumes and observed ones using score $r=V_{\text {scal }} / V_{\text {smeas }}$. The lower interval limit represents $8 \%$ of the total sediment transport and the upper interval limit $16 \%$ of the total transport

\begin{tabular}{ccccc}
\hline & $\begin{array}{c}\text { Total deposited } \\
\text { volume }\left(\mathbf{m}^{3}\right)\end{array}$ & $\begin{array}{c}\text { Simulated } \\
\text { deposition score }\end{array}$ & $\begin{array}{c}\text { Simulated bedload } \\
\text { volume score } \\
\text { Lower Limit }\end{array}$ & $\begin{array}{c}\text { Simulated bedload } \\
\text { volume score } \\
\text { Upper Limit }\end{array}$ \\
\hline MPM x STRICK & 88362 & 1.09 & 13.6 & 6.80 \\
MPM x FERG & 31761 & 0.39 & 4.89 & 2.44 \\
RECK x STRICK & 58354 & 0.71 & 8.99 & 4.49 \\
RECK x FERG & 19885 & 0.24 & 3.06 & 1.53 \\
\hline
\end{tabular}



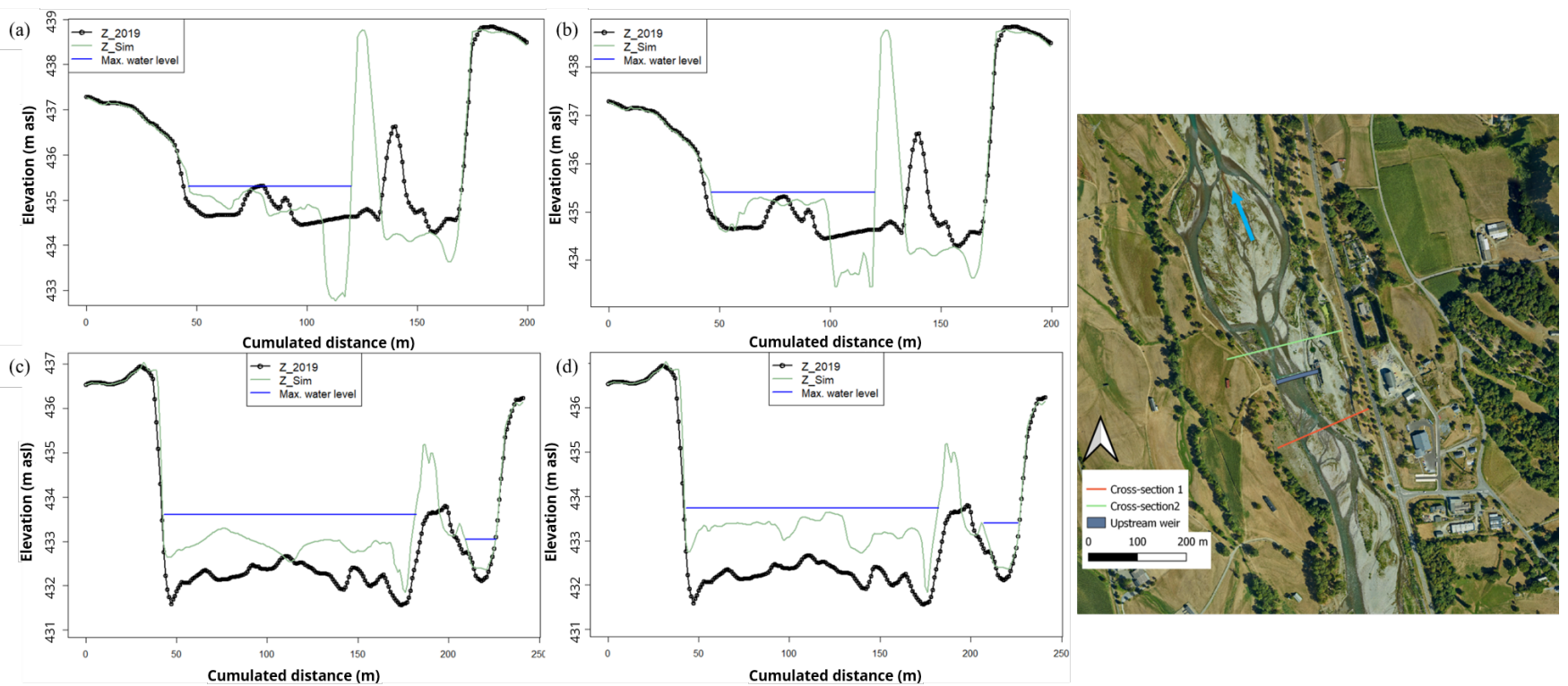

Figure 13. Cross-section comparison upstream (orange cross-section) and downstream (green cross-section) the Beaucens weir (right). The presented simulations were performed with the Ferguson friction law. Left: $(\boldsymbol{a})$ and $(\boldsymbol{b})$ are the usptream cross-sections for the Recking formula and the MPM formula respectively ; $(\boldsymbol{c})$ and $(\boldsymbol{d})$ are the downstream cross-sections for the Recking formula and the MPM formula respectively.

\subsection{Is the BSS adapted to complex morphologies?}

Finally, each simulation was assessed with the BSS since this score was considered relevant for morphological changes evaluation by the recent literature. More than 60 simulations were performed with different model parameters combinations. The best BSS results were obtained for simulations with very little riverbed changes $(\mathrm{BSS}=0.06)$ that have not been presented here. However, this simulation was not the best performing one in terms of deposited volumes and long profile evolution. For the two best-performing simulations according to the longitudinal profile analysis and the deposited volumes (RECK $\mathrm{x}$ FERG and MPM x FERG), the BSS results are poor (-0.04 and -0.12, respectively).

This raises the question of the relevance of the BSS criterion for morphologies as complex as the LDG reach. The fact that the model cannot accurately reproduce the different river branches due to the braiding phenomenon is approached in a very strict manner by the BSS. To our knowledge, models have difficulties predicting channel migration processes that occur in a braided river as this phenomenon is uncertain and random, especially during flood events. Besides, our model was not developed to reproduce braiding phenomena. The aim was to identify erosion and deposition areas and especially evaluate the sediment deposition amounts that might have a strong impact on the downstream fluvial system if the weir suppression or lowering are considered. Although the BSS can be advantageous as it helps to rapidly evaluate the performances of numerous 
simulations, using it on braided and thus complex morphologies does not seem relevant in our study site. In these cases, the modeler's visual critical analysis is still essential.

\subsection{Implementation of restoration scenarios}

The model seems to provide reliable results with the Ferguson friction law, so this formula was selected to perform restoration scenarios simulations. The two bedload transport formulas (MPM and Recking) were considered. The MPM is considered to provide more extreme results that we view as the "worst-case scenario", whereas the Recking formula is considered more realistic or even to minimise the transported volumes.

Two restoration scenarios were performed. A Business as Usual Scenario (BAU) which corresponds to the current situation, where we consider that no restoration measure is implemented. A Weir Lowering scenario (WL), implemented through the modification of the bathymetry, for which the downstream weir (Préchac) is lowered by two meters. To assess the influence of each scenario, two cross-sections upstream and downstream the weir were analysed (Fig. 14).

For each restoration scenario (BAU and WL), the first simulation considered the 2019 topography and a 2018 type flood event is injected. Then another 2018 type flood event is injected on the resulting bathymetries of these two first simulations (Z_Sim_BAU and Z_Sim_WL). As a result, we can have an overview of the LDG reach behaviour depending on the selected restoration measure and the bedload formulas after two 10-year return period-like flood events.

For the BAU scenario, very few morphological changes are observed upstream of the "Préchac" weir. Downstream, some depositions are observed with the MPM formula for the two flood scenarios ( 1 and 2 consecutive 2018 flood events). This consolidates the observations made above regarding the fact that this sediment transport formula tends to estimate more important sediment transport volumes than the Recking one for high flow situations. Very few changes are observed for the Recking formula for the BAU scenario.

As expected, the WL scenario shows more morphological modifications for both sediment transport formulas. Upstream the "Préchac" weir, very few changes are observed for the one 2018 flood event scenario with the MPM formula. However, severe incisions are noticed for the two 2018 flood events scenarios (up to - 2 meters). For the Recking formula, the incision phenomenon is less exacerbated for the two 2018 flood events scenario. The opposite phenomenon is observed downstream for both sediment transport formulas but with different amplitudes. Impressive sediment depositions can be noticed with the MPM formula for the two flood events scenario (up to +2.5 meters). Considerable aggradation for the Recking formula can be observed as well but with a lesser amplitude (up to +1 meter).

The surprising nature of the results is the fact that the reaction of the model with the MPM formula for the one 2018 flood event seems to be very modest, whether it is upstream or downstream the "Préchac" weir. This might be due to the fact that this is a threshold formula and that the critical shear stress might not be exceeded in this area to generate sediment transport and thus morphological modifications. Conversely, as the Recking formula is not a threshold one, partial transport is estimated even for small discharges which can explain the observed morphological changes. 

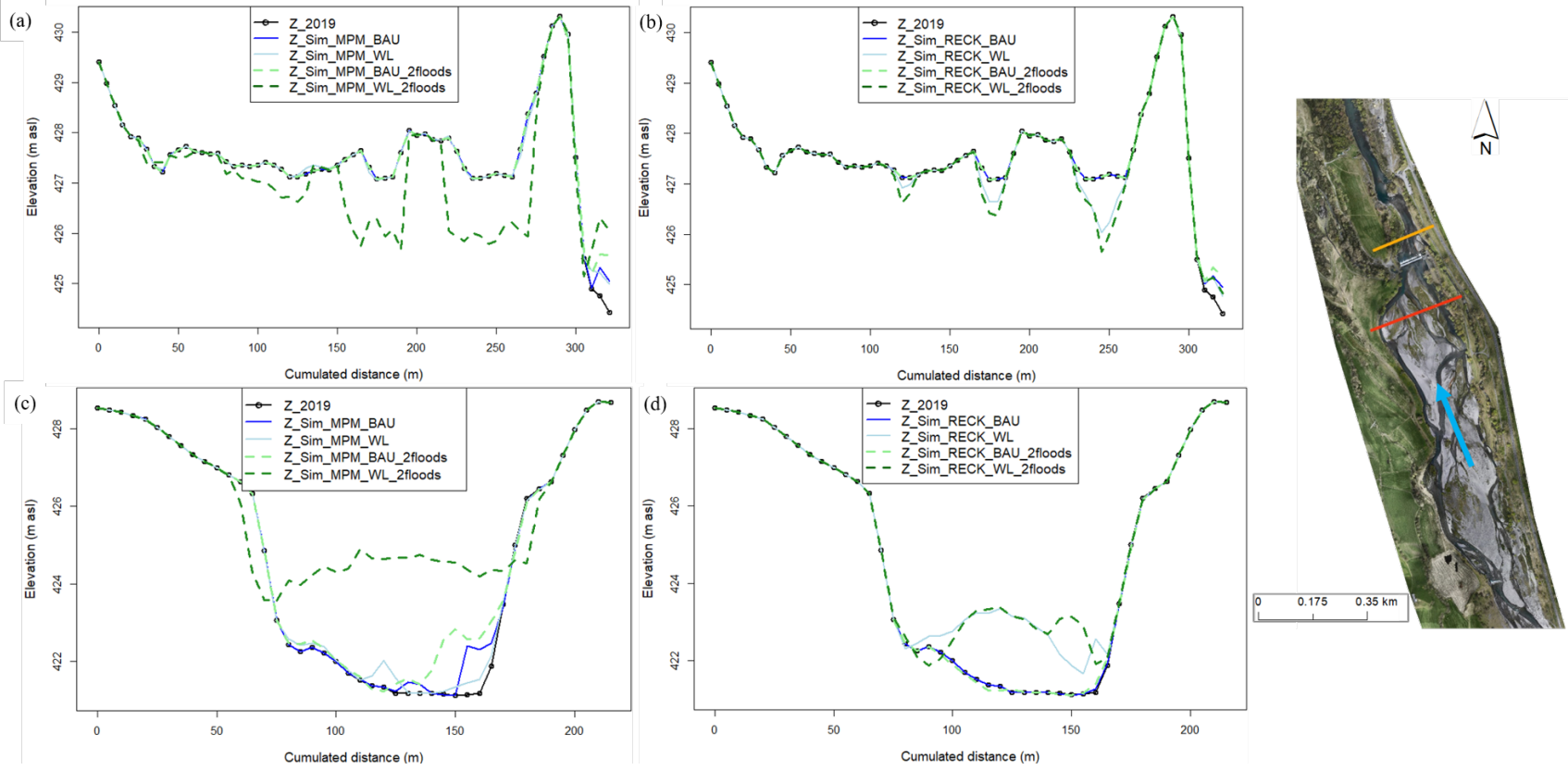

Figure 14. $(\boldsymbol{a})$ and $(\boldsymbol{b})$ are the simulated cross sections for the MPM formula and Recking formula respectively upstream the Préchac weir (red cross-section on the right) for the BAU and the WL scenarios. (c) and $(\boldsymbol{d})$ are the simulated cross-sections for the MPM formula and the Recking formula respectively downstream the Préchac weir (orange cross-section on the right) for the same scenarios

In any case, even if the observed morphological evolution after the weir lowering will considerably enhance the ecological situation of the LDG reach by reactivating the sediment continuity allowing the circulation of anadromous fishes, this scenario might pose serious operational problems for the river managers. The upstream incision can, for example, induce:

- temporary bank erosions that can lead to the loss of portions of agricultural lands ;

- the propagation of the incision upstream until it meets a blocking point (the "Beaucens" weir and then the same problem will be observed) ;

- the lowering of the water table on which the farmers depend ;

- the disconnection of the fishery water intake.

480 The significant depositions observed downstream can increase flood risks knowing that it is already vulnerable as many stakes are located in this area. As we can see in Fig. 14, the simulated river bed with the MPM formula for the two 2018 flood events is very close to the left bank's altitude.

However, our model's observed over-depositions and incisions can be criticized. Indeed, only bedload was considered with coarse sediments and not the total sediment mixture. The suspended load is completely neglected. Still, a significant percentage 
of the LDG is composed of very fine sediments (silt, clay), especially downstream, which might be mobilized quickly after an action on the downstream weir. This means that a portion of the mobilized sediment will certainly be flushed far downstream and not have time to settle and induce the observed modelled morphological changes. Depositions would still be observed but to a lesser extent. Besides, our model only considers one homogeneous grain size in the whole domain, which might also explain the over-depositions observed downstream. A perspective of improvement for the model can thus be to consider the whole grain size distribution spatially distributed over the studied domain to have a more realistic view of the impacts of any restoration measure. This can be done with the brand new sediment transport module "GAIA" developed to handle grain-size issues better.

To sum up, our model reproduces realistic tendencies but can still be improved to make better volumetric estimations. One of the most important recommendations that we gave to the river managers is that if no action is considered in the upstream weir jointly, the problem will just be reported there, and the same consequences will be observed. Besides, in such kinds of complex morphologies, the main advice is to consider an adaptive management strategy with step by step monitoring and eventual corrections if needed.

\section{Conclusion}

The evolution of river morphology is very complicated to predict, especially in the case of mountain and Piedmont rivers with complex morphologies. River restoration in such terrain can thus be challenging for river managers due to the random nature of riverbed evolution. Reliable hydromorphological numerical modelling combined with good field expertise can be helpful in this case for better river management. Within this framework, our study focused on the development of a 2D hydromorphodynamic model over the "Lac des Gaves" reach in the Hautes-Pyrénées, France, with the TELEMAC-MASCARET system. This river reach has precisely the morphological characteristics mentioned above as it is a braided channel with a very heterogeneous grain-size distribution. The aim was to reproduce the channel evolution following the 2018 flood event that considerably impacted the channel's morphology to propose relevant and sustainable restoration solutions. Two bedload transport formulas, the Meyer-Peter-Müller and the Recking one, were used with the Ferguson and the Strickler friction laws to assess sediment transport processes. Three performance criteria were considered to assess the validity of the developed model: the Brier Skill Score, the comparison of longitudinal profiles and the analysis of deposited volumes within the LDG.

510 The 2D hydromorphodynamic model performed realistic simulations with the Ferguson friction law for both sediment transport formulas (Recking and MPM). These results validate the necessity to use a friction formula adapted to river reaches with high relative roughness and significant sediment load. The developed model tends to overestimate sediment depositions within the LDG. This might be due to the fact that it is a monodisperse model, considering bedload only with one homogeneous grain-size whereas in reality, finer sediments are also available. These are likely to be "flushed" and travel longer distances before being deposited, which is not simulated here. The observed modelled morphological changes can thus be considered to overestimate what can actually be noticed on the ground. Further improvements on these aspects are necessary, knowing 
https://doi.org/10.5194/esurf-2021-91

Preprint. Discussion started: 26 January 2022

(c) Author(s) 2022. CC BY 4.0 License.

(c) (i)

the heterogeneity of sediment sizes within the LDG reach. Simulations on the updated sediment transport module GAIA, developed to handle the grain-size distribution issue better, are considered to improve the hydromorphodynamic model.

Moreover, this study shows that the BSS might not be the right performance criterion to consider for rivers with braided morphologies. These complex configurations remain very difficult to reproduce by $2 \mathrm{D}$ models. The BSS score can thus give very pessimistic results, whereas the model correctly reproduces the most important processes (erosion and deposition areas). We recommend considering an integrative approach where the modeller combines multiple assessment criteria such as long profiles and cross-sections evolution and volumetric estimations to judge the model's performance.

Finally, even if our model can still be improved, it provided valuable information on the possible consequences of a restoration scenario to river managers. Many operational issues were raised for the weir lowering scenario, such as the increase of flood risks downstream or severe erosions upstream that can translate the issue to the upstream weir. Knowing the complexity of river restoration projects in these kinds of complex morphologies, considering an adaptive management strategy with a step by step monitoring and eventual corrections might be more appropriate rather than a radical measure. Besides, enhancing the hydromorphodynamic model after considering the whole grain-size distribution and its actualization after each morphogenetic event can be used as a decision-making tool that can assist river managers and help them communicate with the elected representatives.

Author contributions. Rabab Yassine carried out the simulations and the field experiments in collaboration with Hélène Roux, Ludovic Cassan and Olivier Frysou. Rabab Yassine wrote the manuscript with support from Ludovic Cassan and Hélène Roux. François Pérès helped supervise the project and organize stakeholders meeting to communicate the results with the elected representatives.

Acknowledgements. We are grateful to the public institution "Pays de Lourdes et des Vallées des Gaves" for having given us the opportunity to undertake this work. This research was funded by the three following organisms: the Water Agency "Adour-Garonne", the government, the region "Occitanie Pyrénées Méditerranée" whom we thank sincerely. 
https://doi.org/10.5194/esurf-2021-91

Preprint. Discussion started: 26 January 2022

(c) Author(s) 2022. CC BY 4.0 License.

\section{References}

Aguirre, D., Bui, M., Giehl, S., Reisenbüchler, M., and Rutschmann, P.: Development of a hydro-morphodynamic Model for Sediment Management in the Rosenheim Reservoir, https://doi.org/10.5281/zenodo.3611498, 2020.

Arnaud, F.: Approches géomorphologiques historique et expérimentale pour la restauration de la dynamique sédimentaire d'un tronçonfluvial aménagé : le cas du Vieux Rhin entre Kembs et Breisach (France, Allemagne), Ph.D. thesis, Université Lumière Lyon 2, 2012.

Arnaud-Fassetta, G., Astrade, L., Bardou, E., Corbonnois, J., Delahaye, D., Fort, M., Gautier, E., Jacob, N., Peiry, J.-L., Piégay, H., and Penven, M.-J.: Fluvial geomorphology and flood-risk management, Géomorphologie : relief, processus, environnement, vol. 15 - $\mathrm{n}^{\circ} 2$, 2009.

Badoux, A., Andres, N., and Turowski, J. M.: Damage costs due to bedload transport processes in Switzerland, Natural Hazards and Earth System Sciences, 14, 279-294, https://doi.org/10.5194/nhess-14-279-2014, 2014.

Blanpied, J.: La torrentialité dans les Pyrénées centrales : évolution depuis la fin du Petit Âge Glaciaire, spécificités et dynamiques géomorphologiques actuelles, Ph.D. thesis, Université de Toulouse - Jean Jaurès, 2019.

Carr, K. J., Tu, T., Ercan, A., Kavvas, M. L., and Nosacka, J.: Two-Dimensional Unsteady Flow Modeling of Flood Inundation in a Leveed Basin, pp. 1597-1606, https://doi.org/10.1061/9780784479162.156, 2015.

Chapuis, M.: Mobilité des sédiments fluviaux grossiers dans les systèmes fortement anthropisés : éléments pous la gestion de la basse vallée de la Durance, Ph.D. thesis, Université Aix Marseille, 2012.

De Linares, M.: Two-dimensional numerical modelling of bed load transport and fluvial morphology. Validation on two sites on the Loire river and on the Arc river., Theses, Université Joseph-Fourier - Grenoble I, https://tel.archives-ouvertes.fr/tel-00193119, 2007.

de Saint-Venant, M.: Théorie du mouvement non permanent des eaux, avec application aux crues des rivières et à l'introduction des marées dan leur lit, Paris, frei, 1871.

Douinot, A., Roux, H., Garambois, P.-A., and Dartus, D.: Using a multi-hypothesis framework to improve the understanding of flow dynamics during flash floods, Hydrology and Earth System Sciences, 22, 5317-5340, https://doi.org/10.5194/hess-22-5317-2018, 2018.

Einstein, H. A.: The bed-load function for sediment transportation in open channel flows, 1026, US Government Printing Office, 1950.

Exner, F. M.: Zur Physik der Dünen, [S.1.], 1920.

Ferguson, R.: Flow resistance equations for gravel- and boulder-bed streams, Water Resources Research, 43, https://doi.org/10.1029/2006WR005422, 2007.

Gonzales De Linares, M., Mano, V., Piton, G., and Recking, A.: Modelling of massive bedload deposition in a debris basin: cross comparison between numerical and small scale modelling, in: RiverFlow 2020, edited by et al., U., Proceedings of the 10th Conference on Fluvial Hydraulics, Delft, Netherlands, https://hal.archives-ouvertes.fr/hal-02935173, 2020.

Guan, M., Wright, N. G., and Andrew Sleigh, P.: Multiple effects of sediment transport and geomorphic processes within flood events: Modelling and understanding, International Journal of Sediment Research, 30, 371-381, https://doi.org/https://doi.org/10.1016/j.ijsrc.2014.12.001, 2015.

Guan, M., Carrivick, J. L., Wright, N. G., Sleigh, P. A., and Staines, K. E.: Quantifying the combined effects of multiple extreme floods on river channel geometry and on flood hazards, Journal of Hydrology, 538, 256-268, https://doi.org/https://doi.org/10.1016/j.jhydrol.2016.04.004, 2016.

Ham, D. and Church, M.: Morphodynamics of an extended bar complex, Fraser River, British Columbia, Earth Surface Processes and Landforms, 37, 1074-1089, https://doi.org/https://doi.org/10.1002/esp.3231, 2012. 
https://doi.org/10.5194/esurf-2021-91

Preprint. Discussion started: 26 January 2022

(c) Author(s) 2022. CC BY 4.0 License.

Hervouet, J.-M.: Hydrodynamique des écoulements à surface libre : modélisation numérique avec la méthode des éléments finis, Paris :

Presses de l'école nationale des ponts et chaussées, 2003.

IDEALP: Etude d'hydraulique torrentielle et morphodynamique du Bastan, Tech. rep., IDEALP, 2014.

Kang, J. and Yeo, H.: Survey and analysis of the sediment transport for river restoration: The case of the Magyeong river, Open Journal of

Civil Engineering, 2015.

Lepesqueur, J., Hostache, R., Martínez-Carreras, N., Montargès-Pelletier, E., and Hissler, C.: Sediment transport modelling in riverine environments: on the importance of grain-size distribution, sediment density, and suspended sediment concentrations at the upstream boundary, Hydrology and Earth System Sciences, 23, 3901-3915, https://doi.org/10.5194/hess-23-3901-2019, 2019.

Liébault, F., Peteuil, C., Jousse, C., Fragnol, B., Theule, J., Berger, F., Saez, J. L., Gotteland, A., Jaboyedoff, M., and Loye, A.: L’utilisation des plages de dépôts pour la mesure du transport solide torrentiel : applications dans le département de l'Isère, Tech. rep., Conseil général de l'Isère, 2010.

Malavoi, J., Garnier, C. C., Landon, N., Recking, A., and Baran, P.: Eléments de connaissance pour la gestion du transport solide en rivière, ONEMA, 2011.

Meyer-Peter, E. and Müller, R.: Formulas for Bed-Load Transport, in: 2nd meeting of the International Association for Hydraulic Structures Research, Stockholm, 1948.

Misset, C., Recking, A., Legout, C., Bakker, M., Bodereau, N., Borgniet, L., Cassel, M., Geay, T., Gimbert, F., Navratil, O., Piegay, H., Valsangkar, N., Cazilhac, M., Poirel, A., and Zanker, S.: Combining multi-physical measurements to quantify bedload transport and morphodynamics interactions in an Alpine braiding river reach, Geomorphology, 351, 106877, https://doi.org/https://doi.org/10.1016/j.geomorph.2019.106877, 2020.

Orseau, S., Huybrechts, N., Tassi, P., Pham Van Bang, D., and Klein, F.: Two-dimensional modeling of fine sediment transport with mixed sediment and consolidation: Application to the Gironde Estuary, France, International Journal of Sediment Research, 36, 736-746, https://doi.org/https://doi.org/10.1016/j.ijsrc.2019.12.005, 2021.

PLVG: Mise en place d'un Programme d'Actions de Prévention des Inondations (PAPI) sur le bassin versant du Gave de Pau Bigourdan Etat des lieux - Diagnostic, Tech. rep., PLVG, 2015.

600 Recking, A.: A comparison between flume and field bed load transport data and consequences for surface-based bed load transport prediction, Water Resources Research, 46, https://doi.org/10.1029/2009WR008007, 2010.

Recking, A.: Simple method for calculating reach-averaged bed-load transport, Journal of Hydraulic Engineering, 139, 70-75, 2013a.

Recking, A.: An analysis of nonlinearity effects on bedload transport prediction, Journal of Geophysical Research, 118, p. 1264 - p. 1281 , https://doi.org/10.1002/jgrf.20090, 2013b.

Recking, A., Leduc, P., Liébault, F., and Church, M.: A field investigation of the influence of sediment supply on step-pool morphology and stability, Geomorphology, 139-140, 53 - 66, https://doi.org/https://doi.org/10.1016/j.geomorph.2011.09.024, 2012.

Recking, A., Piton, G., Vazquez-Tarrio, D., and Parker, G.: Quantifying the Morphological Print of Bedload Transport, Earth Surface Processes and Landforms, 41, 809-822, https://doi.org/10.1002/esp.3869, 2016.

Reid, S. C., Lane, S. N., Berney, J. M., and Holden, J.: The timing and magnitude of coarse sediment transport events within an upland, temperate gravel-bed river, Geomorphology, 83, 152 - 182, https://doi.org/https://doi.org/10.1016/j.geomorph.2006.06.030, 2007.

Reisenbüchler, M., Bui, M. D., Skublics, D., and Rutschmann, P.: Enhancement of a numerical model system for reliably predicting morphological development in the Saalach River, International Journal of River Basin Management, 0, 1-13, https://doi.org/10.1080/15715124.2019.1628034, 2019. 
https://doi.org/10.5194/esurf-2021-91

Preprint. Discussion started: 26 January 2022

(c) Author(s) 2022. CC BY 4.0 License.

(c) (i)

Rickenmann, D. and Recking, A.: Evaluation of flow resistance in gravel-bed rivers through a large filed data set, Water resources research, 2011.

Rickenmann, D., Badoux, A., and Hunzinger, L.: Significance of sediment transport processes during piedmont floods: the 2005 flood events in Switzerland, Earth Surface Processes and Landforms, 41, 224-230, https://doi.org/10.1002/esp.3835, 2016.

Rinaldi, M. and Darby, S. E.: 9 Modelling river-bank-erosion processes and mass failure mechanisms: progress towards fully coupled simulations, in: Gravel-Bed Rivers VI: From Process Understanding to River Restoration, edited by Habersack, H., Piégay, H., and Rinaldi, M., vol. 11 of Developments in Earth Surface Processes, pp. 213-239, Elsevier, https://doi.org/https://doi.org/10.1016/S0928-2025(07)111263, 2007.

Roux, H., Labat, D., Garambois, P.-A., Maubourguet, M.-M., Chorda, J., and Dartus, D.: A physically-based parsimonious hydrological model for flash floods in Mediterranean catchments, Natural Hazards and Earth System Sciences, 11, 2567-2582, https://doi.org/10.5194/nhess-11-2567-2011, 2011.

Roux, H., Amengual, A., Romero, R., Bladé, E., and Sanz-Ramos, M.: Evaluation of two hydrometeorological ensemble strategies for flash-flood forecasting over a catchment of the eastern Pyrenees, Natural Hazards and Earth System Sciences, 20, 425-450, https://doi.org/10.5194/nhess-20-425-2020, 2020.

Strickler, A.: Beiträge zur Frage der Geschwindigkeitsformel und der Rauhigkeitszahlen für Ströme, Kanäle und geschlossene Leitungen: mit... Tab., Im Selbstverlag, 1923.

630 SUEZConsulting: Étude hydraulique et AMC pour évaluer l'intérêt de considérer la Voie Verte des Gaves comme un ouvrage de protection contre les crues. Phase 2 : Diagnostic - étude hydrologique, Tech. rep., PLVG, 2019.

Sutherland, J., Peet, A., and Soulsby, R.: Evaluating the performance of morphological models, Coastal Engineering, 51, 917 - 939 , https://doi.org/https://doi.org/10.1016/j.coastaleng.2004.07.015, coastal Morphodynamic Modeling, 2004.

Tal, M. and Paola, C.: Effects of vegetation on channel morphodynamics: results and insights from laboratory experiments, Earth Surface Processes and Landforms, 2010.

Tassi, P. and Villaret, C.: Sisyphe User Manual, 2014.

Tu, T., Carr, K. J., Ercan, A., Trinh, T., Kavvas, M. L., and Nosacka, J.: Assessment of the effects of multiple extreme floods on flow and transport processes under competing flood protection and environmental management strategies, Science of The Total Environment, 607-608, 613-622, https://doi.org/https://doi.org/10.1016/j.scitotenv.2017.06.271, 2017.

van Rijn, L. C.: Sediment Transport, Part I: Bed Load Transport, 110, 1431-1456, https://doi.org/10.1061/(asce)07339429(1984)110:10(1431), 1984.

Wilcock, P. R. and Crowe, J. C.: Surface-based transport model for mixed-size sediment, Journal of Hydraulic Engineering, 129, 120-128, 2003.

Wohl, E., Bledsoe, B. P., Jacobson, R. B., Poff, N. L., Rathburn, S. L., Walters, D. M., and Wilcox, A. C.: The Natural Sediment Regime in

Rivers: Broadening the Foundation for Ecosystem Management, BioScience, 65, 358-371, https://doi.org/10.1093/biosci/biv002, 2015.

Wolman, G.: A method of sampling coarse river-bed material, Transactions, American Geophysical Union, 1954. 